\title{
Der Bundestag zwischen »Vorratsbeschluss« und Rückholrecht: Plädoyer für ein wirkungsvolles Parlamentsbeteiligungsgesetz
}

\section{Einleitung}

Obwohl die Diskussion um ein Entsende- oder besser Parlamentsbeteiligungsgesetz ${ }^{1}$ zur näheren Regelung der Zusammenarbeit von Bundestag und Bundesregierung bei Entscheidungen über die deutsche Beteiligung an Einsätzen bewaffneter Streitkräfte im Ausland spätestens seit dem Jahre 2001 unvermindert anhält, ${ }^{2}$ ist das Verfahren der Zusammenarbeit zwischen Bundestag und Bundesregierung bei solchen Entscheidungen bis heute nicht näher geregelt. Dies erstaunt umso mehr, als bereits das Grundsatzurteil des Bundesverfassungsgerichts vom 12. Juli $1994^{3}$ hierzu folgende Empfehlung abgab:

»Jenseits dieser (im Urteil zuvor dargelegten) Mindestanforderungen und Grenzen des Parlamentsvorbehalts sind das Verfahren und die Intensität der Beteiligung des Bundestages (bei Entscheidungen über Auslandseinsätze) ${ }^{4}$ in der Verfassung nicht im Einzelnen vorgegeben. Es ist Sache des Gesetzgebers, die Form und das Ausmaß der parlamentarischen Mitwirkung näher auszugestalten. Je nach dem Anlass und den Rahmenbedingungen des Einsatzes bewaffneter Streitkräfte sind unterschiedliche Formen der Mitwirkung denkbar. Insbesondere im Hinblick auf unterschiedliche Arten der Einsätze, vor allem bei solchen, die keinen Aufschub dulden oder erkennbar von geringer Bedeutung sind, empfiehlt es sich, den Zeitpunkt und die Intensität der Kontrolle des Parlaments näher zu umgrenzen. Dabei kann es angezeigt sein, im Rahmen völkerrechtlicher Verpflichtungen die parlamentarische Beteiligung nach der Regelungsdichte abzustufen, in der die Art des möglichen Einsatzes der Streitkräfte bereits durch ein vertraglich geregeltes Programm militärischer Integration vorgezeichnet ist. ${ }^{5}$

1 Dieter Wiefelspütz, Der Einsatz bewaffneter deutscher Streitkräfte und der konstitutive Parlamentsvorbehalt, Nomos-Verlag Baden-Baden, 1. Aufl. 2003 (zitiert als »Parl.-vorbehalt «); ders.: Der Einsatz der Streitkräfte und die konstitutive Beteiligung des Deutschen Bundestages (zitiert als »Beteiligung «), Neue Zeitschrift für Wehrrecht (NZWehrr) 2003, S. $133 \mathrm{ff}$. [134]; vgl. die Diskussionsbeiträge beim Forum der Deutschen Vereinigung für Parlamentsfragen e. V. zum Thema »Auslandseinsätze der Bundeswehr zwischen Parlaments- und Regierungsinteresse - Probleme eines Entsendegesetzes « - am Mittwoch, 4. Juni 2003, im Kaisersaal der Deutschen Parlamentarischen Gesellschaft, dokumentiert im Protokoll (zitiert als DVParl-Protokoll vom 04.06.2003): MdB Hans-Peter Bartels (SPD), S. 15, Prof. Josef Isensee (Universität Bonn als Moderator), S. 29 sowie Prof. Rupert Scholz (CDU, BM a. D.), S. 34, nach dessen Auffassung der Titel des Gesetzes nicht im Vordergrund steht; vgl. ferner Darstellung bei Peter Dreist, Offene Rechtsfragen des Einsatzes bewaffneter deutscher Streitkräfte - Zwischenbilanz und Problemaufriss, NZWehrr 2002, S. 133 ff. [143] = Unterrichtsblätter für die Bundeswehrverwaltung (UBWV) 6/2003, S. 201 ff..

2 Peter Dreist, a. a. O. (Fn. 1), insbes. S. $134-137$.

3 BVerfGE 90, 286 ff. [389].

4 Zusätze durch den Autor.

5 BVerfGE 90, 286 [389]. 
Da Bundesregierung und Deutscher Bundestag nach dem Judikat zwar ebenso wie die Rechtswissenschaft ${ }^{6}$ erste Überlegungen anstellten, wie diese Vorgaben des höchsten deutschen Gerichts umzusetzen sein könnten, diese Initiativen dann aber erlahmten, blieb es zunächst einer allmählich wachsenden und zunehmend ausgefeilten Staatspraxis überlassen, die Einzelheiten des Verfahrens einzelfallbezogen zu regeln. Trotz wiederholter Hinweise in jüngerer Zeit auf die Notwendigkeit eines solchen Gesetzes durch Rechtswissenschaft, ${ }^{7}$ Politik ${ }^{8}$ und auch die ehemalige Präsidentin des Bundesverfassungsgerichts Jutta Limbach ${ }^{9}$ ist jedoch bisher ein solches Gesetz nicht verabschiedet worden. In diesem Beitrag soll zunächst dargelegt werden, welche weiteren Vorgaben des Bundesverfassungsgerichts zu bewaffneten Einsätzen (2) und zu Gefahr im Verzug zu beachten sind (3) und wie das bisherige Verfahren der Parlamentsbeteiligung abläuft (4). Außerdem soll dargelegt werden, welche Fragen sich in den Ausschüssen und im Plenum des Deutschen Bundestages immer wieder bei Einsatzentscheidungen stellen (5), welche Fragen sich für die Regierungspraxis bei der Zusammenarbeit mit dem Deutschen Bundestag immer wieder erheben (6), welche

6 Vgl. z. B. Klaus Dau, Parlamentsheer unter dem Mandat der Vereinten Nationen - Anmerkungen zu dem Urteil des Bundesverfassungsgerichts vom 12. Juli 1994 zu den Auslandsverwendungen deutscher Streitkräfte - NZWehrr 1994, S. 177 ff.; Georg Nolte, Bundeswehreinsätze in kollektiven Sicherheitssystemen - Zum Urteil des Bundesverfassungsgerichts vom 12. Juli 1994, Zeitschrift für ausländisches öffentliches Recht und Völkerrecht (ZaöRV) 1994, S. 652 ff.

7 Vgl. Michael Wild, Verfassungsrechtliche Möglichkeiten und Grenzen für Auslandseinsätze der Bundeswehr nach dem Kosovo-Krieg - Versuch einer Systematisierung - Die Öffentliche Verwaltung (DÖV) 2000, S. 622 ff.; Stefan Oeter, Einsatzarten der Streitkräfte außer zur Verteidigung - Verfassungsrechtliche Grundlagen, NZWehrr 2000, S. 89 ff.; Christian Burkiczak, Ein Entsendegesetz für die Bundeswehr?, Zeitschrift für Rechtspolitik (ZRP) 2003, S. 82 ff.; vgl. ferner Fn. 1 und 2.

8 BT-Drs. 14/9402 vom 12.06.2002, Antrag der Abgeordneten Jörg van Essen, Günther Friedrich Nolting, Dr. Edzard Schmidt-Jortzig u. a. und der Fraktion der FDP »Rechtssicherheit für die bewaffneten Einsätze deutscher Streitkräfte schaffen - ein Gesetz zur Mitwirkung des Deutschen Bundestages bei Auslandseinsätzen der Bundeswehr einbringen.«BT-Drs. 15/36 vom 06.11.2002, Antrag der Abgeordneten Dr. Werner Hoyer, Jörg van Essen, Günther Friedrich Nolting u. a. und der Fraktion der FDP mit demselben Titel wie in der 14. Legislaturperiode. Undatierter Gesetzentwurf (Arbeitspapier) der Abgeordneten und der Fraktion der CDU/CSU aus dem Frühjahr 2003 (ca. 27.03.2003) »Entwurf eines Entsendegesetzes«. Positionspapier der Bundestagsfraktion Bündnis 90 / Die Grünen - Parlamentsbeteiligungsgesetz - vom 17.10.2003. Entwurf der SPD-Bundestagsfraktion für ein Parlamentsbeteiligungsgesetz vom 20.10.2003. Gesetzentwurf der Abgeordneten und der Fraktion der FDP zum »Entwurf eines Gesetzes zur Mitwirkung des Deutschen Bundestages bei Auslandseinsätzen der Bundeswehr « (Auslandseinsätzemitwirkungsgesetz), vorgestellt in Berlin am 11.11.2003. Gemeinsamer »Entwurf von SPD und Bündnis 90/Grüne für ein Parlamentsbeteiligungsgesetz vom 27.11.2003

9 dpa-Meldung vom 17.03.2002 über ein Interview der scheidenden Präsidentin des Bundesverfassungsgerichts mit dem Südwestrundfunk »Limbach empfiehlt Entsendegesetz für Soldateneinsätze«. Danach solle der Gesetzgeber in einem Entsendegesetz die Einsätze deutscher Soldaten bei Friedenseinsätzen sowie die Informationsrechte und -pflichten von Parlament und Regierung regeln. Vgl. ferner die von RDir Lothar Speckmann aufgelegte und betreute Web-Seite http://www.deutsches-wehrrecht.de/, Menüpunkt »Aktuelle Meldungen«, dort Thema »Forderungen nach einem Entsendegesetz für Bundeswehr-Einsätze«. 
Gemeinsamkeiten es bei den bisherigen Vorschlägen der Parteien zu einem Parlamentsbeteiligungsgesetz gibt (7) und welche Inhalte ein Gesetzentwurf mindestens haben müsste (8). Sodann soll ein Gesetzentwurf vorgeschlagen werden, der als Basis für die weiter Diskussion dienen könnte (9) und mit einem Ausblick (10) geschlossen werden. In diesem Zusammenhang wird die Darstellung auf die gegenwärtig geltende Rechtslage und die dadurch bestehenden Einsatzoptionen beschränkt.

Dabei ist es wichtig, darauf hinzuweisen, dass auf diesem bisher völlig ungeregelten Feld zunächst einmal jeder Vorschlag diskussionswürdig ist und eine Reihe offener Fragen der Staatspraxis dringend regelungsbedürftig sind. In diesem Beitrag wird eine Variante vorgestellt, die sich weitgehend an den bisherigen Vorgaben des Bundesverfassungsgerichts orientiert, dabei jedoch in einigen Fällen vertretbare und praktikable Varianten vorschlägt.

\section{Vorgaben des Bundesverfassungsgerichts zu bewaffneten Einsätzen}

Gegenstand einer Parlamentsbeteiligung - so das Bundesverfassungsgericht - seien Einsätze bewaffneter Streitkräfte. ${ }^{10}$ Das Grundgesetz ermächtige den Bund, Streitkräfte zur Verteidigung aufzustellen (Art. 87a Abs. 1 Satz 1 GG). Es ermächtige den Bund ferner, sich Systemen kollektiver Selbstverteidigung und gegenseitiger kollektiver Sicherheit anzuschließen; darin sei auch die Befugnis eingeschlossen, sich mit eigenen Streitkräften an Einsätzen zu beteiligen, die im Rahmen solcher Systeme vorgesehen seien und nach ihren Regeln stattfänden. ${ }^{11}$ Während die auswärtige Gewalt von der Verfassung weitgehend dem Kompetenzbereich der Exekutive zugeordnet werde, ${ }^{12}$ sähen die grundgesetzlichen Regelungen über die Wehrverfassung für den Einsatz bewaffneter Streitkräfte grundsätzlich eine Beteiligung des Parlament vor. ${ }^{13}$ Die auf die Streitkräfte bezogenen Regelungen des Grundgesetzes seien - in den verschiedenen Abstufungen - stets darauf angelegt, die Bundeswehr nicht als Machtpotential allein der Exekutive zu überlassen, sondern als »Parlamentsheer « in die demokratisch-rechtsstaatliche Verfassungsordnung einzufügen, d. h. dem Parlament einen rechtserheblichen Einfluss auf Aufbau und Verwendung der Streitkräfte zu sichern. ${ }^{14}$

10 BVerfGE 90, 286 [387].

11 BVerfGE 90, 286 [381]. Hier schloss sich das Bundesverfassungsgericht einer in der Rechtswissenschaft vertretenen Auffassung an, die bis zu diesem Zeitpunkt als absolute Mindermeinung galt; vgl. Raimond Emde, Voraussetzungen für die Zulässigkeit eines Bundeswehreinsatzes innerhalb und außerhalb der NATO, NZWehrr 1992, S. 133 ff. [134]; Gilbert Gornig, Eine Verfassungsänderung ist nicht erforderlich, Truppenpraxis 5/1993, S. 571 ff. [576, 578]; ders.: Die Verfassungsmäßigkeit der Entsendung von Bundeswehrsoldaten zu »Blauhelm«-Einsätzen, Juristenzeitung (JZ) 1993, S. 123 ff. [124]; vgl. ferner die Darstellung des Streitstandes vor dem Grundsatzjudikat vom 12. Juli 1994 bei Peter Dreist, Auslandseinsätze der Bundeswehr ohne Grenzen? Bundeswehrverwaltung (BWV) 1994, S. 125 ff.; vgl. statt vieler DVParl-Protokoll vom 04.06.2003, dort Josef Isensee, S. 10, der vom »Orakel von Karlsruhe« spricht.

12 BVerfGE 90, 286 [357 ff.].

13 BVerfGE 90, 286 [381].

14 BVerfGE 90, 286 [382]. 
Ausdruck eines ausgeprägten Systems der parlamentarischen Kontrolle über die Bundeswehr seien insbesondere Art. 45a GG (soweit ein Ausschuss für Verteidigung vorgesehen ist, der mit den Rechten eines Untersuchungsausschusses ausgestattet ist), Art. 45b GG (Wehrbeauftragter) und Art. 87a Abs. 1 Satz 2 GG (Budgetrecht). ${ }^{15}$ Das Grundgesetz behalte dem Parlament hinsichtlich der Streitkräfte jedoch nicht nur die Kontrolle und eine grundsätzliche Steuerung von Planungen und Entwicklungen vor, sondern auch konkrete Entscheidungen über deren Verwendung. ${ }^{16}$

Vor allem der Übergang der Befehlsgewalt vom Bundesminister der Verteidigung auf den Bundeskanzler nach Art. 115b GG zeige, dass die Feststellung des Verteidigungsfalles durch das Parlament gemäß Art. 115a Abs. 1 GG zugleich zum militärischen Einsatz der Streitkräfte ermächtige. ${ }^{17}$ Die Bündnisklausel des Art. 80a Abs. 3 GG gestatte keinen Streitkräfteeinsatz in alleiniger Kompetenz der Exekutive; die Vorschrift betreffe die nach Maßgabe des NATO-Alarmsystems ausgelöste »zivile Teilmobilmachung «, nicht den Streitkräfteeinsatz im Bündnisfall. ${ }^{18}$

Soweit die Streitkräfte im Verteidigungsfall auch befugt oder ermächtigt werden könnten, zivile Objekte zu schützen und Aufgaben der Verkehrsregelung wahrzunehmen (Art. 87a Abs. 3 GG), ergebe sich die Mitwirkung der gesetzgebenden Körperschaften aus der vom Bundestag mit Zustimmung des Bundesrates gemäß Art. 115a Abs. 1 GG zu treffenden, vorherigen Feststellung des Verteidigungsfalles. ${ }^{19}$ Ein nach Art. 87a Abs. 4 Satz 1 GG möglicher Einsatz von Streitkräften beim Schutz von zivilen Objekten und bei der Bekämpfung organisierter und militärisch bewaffneter Aufständischer sei einzustellen, wenn der Bundestag oder der Bundesrat es verlangten (Satz 2 des Art. 87a Abs. 4 GG). Der Einsatz von Streitkräften zur Unterstützung der Polizeikräfte bei Naturkatastrophen oder Unglücksfällen, die das Gebiet mehr als eines Landes beträfen, werde vom Grundgesetz vor allem als bundesstaatliches Problem verstanden: er sei jederzeit auf Verlangen des Bundesrates aufzuheben (Art. 35 Abs. 3 Satz 2 GG). ${ }^{20}$ Inwiefern die verfassungsrechtliche Aufhebungsoption eines solchen Einsatzes durch den Bundesrat - also eine Vertretung der Regierungen der Bundesländer (vgl. Art. 51 Abs. 1 Satz 1 GG) - Ausdruck eines ausgeprägten Systems der parlamentarischen Kontrolle über die Bundeswehr sein soll, bleibt allerdings unklar. Dasselbe gilt für die Option der Einstellung eines Streitkräfteeinsatzes im inneren Notstand durch den Bundesrat, wobei gemäß Art. 87a Abs. 4 Satz 2 GG die Einstellung allerdings auch durch den Bundestag bewirkt werden kann.

Während die Aufhebung des inneren Notstandes immerhin auch der parlamentarischen Kontrolle durch den Bundestag unterliegt, wäre festzuhalten, dass eine besondere Klausel für die parlamentarische Beteiligung in den Fällen des Art. 35 Abs. 2 und Abs.

15 Art. 87a Abs. 1 GG lautet: «Der Bund stellt Streitkräfte zur Verteidigung auf. Ihre zahlenmäßige Stärke und die Grundzüge ihrer Organisation müssen sich aus dem Haushaltsplan ergeben. " (Hervorhebung des Satzes 2 durch den Autor).

16 BVerfGE 90, 286 [385].

17 BVerfGE 90, 286 [386].

18 BVerfGE a. a. O. (Fn. 17) sowie S. 387.

19 BVerfGE a. a. O. (Fn. 17).

20 BVerfGE 90, 286 [387]. 
$3 \mathrm{GG}$, also sowohl beim Einsatz der Streitkräfte im regionalen als auch beim überregionalen Katastrophennotstand fehlt, so dass eine verfassungsrechtliche Lücke im gegenwärtigen System der Parlamentsbeteiligung besteht. Art. 80a Abs. 1 Satz 1 GG verlangt hingegen für die gesonderte und isolierte Feststellung des Spannungsfalles eine Feststellung des Bundestages über den Eintritt des Spannungsfalles oder die besondere Zustimmung des Bundestages zur Anwendung des Art. 80a GG und derjenigen Rechtsvorschriften, die nur nach Maßgabe dieses Artikels angewendet werden dürfen. Nach Satz 2 des Art. 80a Abs. 1 GG bedürfen diese Feststellungen einer Mehrheit von zwei Dritteln der abgegebenen Stimmen. Die Parlamentsbeteiligung im Fall der Einsatzoptionen Spannungs- und Verteidigungsfall sowie die besonderen Befugnisse der Bundeswehr im sog »äußeren« (Art. 87a Abs. 3 GG), »inneren« (Art. 87a Abs. 4 Satz 1 GG) und »Katastrophen «-Notstand (Art. 35 Abs. 2 und 3 GG) sind jedoch bis auf die Fälle des Art. 35 Abs. 2 Satz 2 und Abs. 3 GG alle im Grundgesetz selbst geregelt und sollen in diesem Beitrag deshalb nicht mehr näher betrachtet werden.

Für die Beteiligung bewaffneter deutscher Streitkräfte an Einsätzen im Ausland hat das Bundesverfassungsgericht folgende weitere Vorgaben entwickelt: Die (verfahrensgegenständlichen $)^{21}$ von der Bundesregierung beschlossenen Einsätze deutscher Streitkräfte, denen jeweils ein vom Sicherheitsrat der Vereinten Nationen erteiltes Mandat zugrunde liege, fänden ihre verfassungsrechtliche Grundlage in Art. 24 Abs. 2 GG, der den Bund ermächtige, sich einem System gegenseitiger kollektiver Sicherheit einzuordnen. Art. 87a Abs. 2 GG stehe dieser Auslegung des Art. 24 Abs. 2 GG nicht entgegen. ${ }^{22}$ Gegenstand einer Parlamentsbeteiligung seien die Einsätze bewaffneter Streitkräfte. Im Fall eines Angriffs auf einen Bündnispartner habe das Parlament der Beistandsverpflichtung zwar schon in Form des nach Art. 59 Abs. 2 GG erforderlichen Gesetzes (bei der Zustimmung zum Transformationsgesetz, das den Gründungs- oder Beitrittsvertrag zum Bestandteil der nationalen Rechtsordnung macht) zugestimmt und damit grundsätzlich gebilligt, dass deutsche Streitkräfte bei Eintritt des Bündnisfalles zum Einsatz kommen. Auch in diesem Fall bedürfe es jedoch noch der - regelmäßig vorhergehenden - parlamentarischen Entscheidung über den konkreten Einsatz nach Maßgabe der bestehenden Bündnisverpflichtungen. ${ }^{23}$

21 Deutsche Beteiligung an den Operation SHARP GUARD und DENY FLIGHT - vgl. den nachträglichen Beschluss des Deutschen Bundestages: BT-Drs. 12/8303 vom 19.07.1994, Zustimmung des Deutschen Bundestages vom 22.07.1994, sowie Hilfseinsatz der Bundeswehr für humanitäre Maßnahmen der Vereinten Nationen in Somalia (Operation UNOSOM II). $\mathrm{Zu}$ letzterem Einsatz war jedoch vor Einsatzbeginn ebenfalls ein Beschluss des Deutschen Bundestages gefasst worden, auch wenn dieser auf einem Antrag der Fraktionen der CDU/CSU und FDP beruht: BT-Drs. 12/4759 vom 21.04.1993, Zustimmung des Deutschen Bundestages am selben Tage. Vgl. im übrigen BVerfGE 90, 286 [345 ff.].

22 BVerfGE 90, 286 [345; $355 \mathrm{ff}$.$] .$

23 BVerfGE 90, 286 [387]. Beispiele hierfür sind die bisherigen Entscheidungen zum Einsatz bewaffneter deutscher Streitkräfte bei der Unterstützung der gemeinsamen Reaktion auf terroristische Angriffe gegen die USA auf Grundlage des Artikels 51 der Satzung der Vereinten Nationen und des Artikels 5 des Nordatlantikvertrages sowie der Resolution 1368 (2001) und 1373 (2001) des Sicherheitsrats der Vereinten Nationen (Feststellung des NATOBündnisfalles am 4. Oktober 2001 - Operation ENDURING FREEDOM), begonnen mit BT-Drs. 14/7296 vom 07.11.2001, Zustimmung des Deutschen Bundestages am 16.11.2001; verlängert am 06.11.2002 und am 14.11.2003. 
Bei Einsätzen bewaffneter Streitkräfte im Rahmen von Resolutionen des Sicherheitsrates sei die vorherige Zustimmung des Bundestages unabhängig davon erforderlich, ob den Streitkräften Zwangsbefugnisse nach Kapitel VII SVN eingeräumt seien und wie die Kommandostrukturen ausgestaltet seien. Eine unterschiedliche Behandlung der verschiedenen Einsatzformen von Friedenstruppen verbiete sich, weil die Grenzen zwischen traditionellen Blauhelmeinsätzen und solchen mit der Befugnis zu bewaffneten Sicherungsmaßnahmen in der Realität fließend geworden seien. Auch werde der Begriff der Selbstverteidigung, die schlichten Friedenstruppen erlaubt sei, bereits in einem aktiven Sinne dahin definiert, dass sie auch den Widerstand gegen gewaltsame Versuche einschließe, die Truppen an der Ausführung ihres Auftrages zu hindern. ${ }^{24}$ Nicht der Zustimmung des Bundestages bedürfe die Verwendung von Personal der Bundeswehr für Hilfsdienste und Hilfeleistungen im Ausland, sofern die Soldaten dabei nicht in bewaffnete Unternehmungen einbezogen seien. ${ }^{25}$ Die Bundesregierung kann diese Vorgabe des Judikats nicht ohne Weiteres umsetzen, sondern muss vor einem solchen Einsatz in einer Prognose prüfen, ob die Gefahr der Einbeziehung in bewaffnete Unternehmungen besteht. Ist diese Gefahr zu besorgen, ist der Bundestag um seine - grundsätzlich vorherige - konstitutive Zustimmung zu ersuchen. ${ }^{26}$

\section{Vorgaben des Bundesverfassungsgerichts zu Gefahr im Verzug}

Die verfassungsrechtlich gebotene Mitwirkung des Bundestages bei konkreten Entscheidungen über den Einsatz bewaffneter Streitkräfte dürfe die militärische Wehrfähigkeit und die Bündnisfähigkeit der Bundesrepublik Deutschland nicht beeinträchtigen. Deshalb sei die Bundesregierung bei Gefahr im Verzug berechtigt, vorläufig den Einsatz von Streitkräften $\mathrm{zu}$ beschließen und an entsprechenden Beschlüssen in den Bündnissen oder internationalen Organisationen ohne vorherige Ermächtigung durch das Parlament mitzuwirken und sie vorläufig zu vollziehen. Die Bundesregierung müsse jedoch in jedem Fall das Parlament umgehend mit dem so

24 BVerfGE 90, 286 [388]. Beispiele sind die Einsätze IFOR in Kroatien (BT-Drs. 13/3122 vom 28.11.1995, Zustimmung des Deutschen Bundestages am 06.12.1995); SFOR in Bosnien-Herzegowina (BT-Drs. 13/10977 vom 17.06.1998, Zustimmung des Deutschen Bundestages am 19.06.1998 - gilt bis heute fort); KFOR im Kosovo und - mit der Zustimmung angrenzender Staaten - dort zu den Zwecken Zugang und Versorgung, begonnen mit BTDrs. 14/1133 vom 11.06.1999, Zustimmung des Deutschen Bundestages am selben Tage seither jährlich um jeweils 12 Monate verlängert; ISAF in Afghanistan (begonnen mit BTDrs. 14/7930 vom 21.12.2001, Zustimmung des Deutschen Bundestages am 22.12.2001; seither mehrfach verlängert.

25 BVerfG a. a. O. (Fn. 24). Beispiele: Einsatz unbewaffneter Militärbeobachter und Sanitätskräfte bei UNOMIG in Georgien (seit 1994) oder Teilnahme von 75 Soldaten der Bundeswehr, die zum Auswärtigen Amt abgeordnet und in Zivil eingesetzt wurden, an der OSZE Kosovo Verification Mission im Kosovo von November 1998 bis zum 20.03.1999. Vgl. auch Darstellung bei Dieter Wiefelspütz (Parl.-vorbehalt - Fn. 1), S. 25 bis 29.

26 Vgl. die Darstellung zu den materiellen rechtlichen Voraussetzungen bei verschiedenen Einsatzvarianten bei Peter Dreist, Prüfschema: Einsatz bewaffneter deutscher Streitkräfte im Ausland, NZWehrr 2003, S. 152 ff. [157]. 
beschlossenen Einsatz befassen. ${ }^{27}$ Die Streitkräfte seien zurückzurufen, wenn es der Bundestag verlange. Dem Gesetzgeber bleibe es unbenommen, die Voraussetzungen eines solchen Notfalls und das dabei zu beobachtende Verfahren näher zu regeln. ${ }^{28}$ An dieser Stelle weist das Gericht ausdrücklich auf seine bereits dargelegten Empfehlungen zu einer gesetzlichen Regelung des Beteiligungsverfahrens hin. ${ }^{29}$ Der Bundestag habe über Einsätze bewaffneter Streitkräfte nach Maßgabe des Art. 42 Abs. 2 GG zu beschließen (also entsprechend dem Verfahren bei der Gesetzgebung). Der Bedeutung des zu fassenden Beschlusses werde es, so es die Lage irgend erlaube, entsprechen, dass er in den zuständigen Ausschüssen vorbereitet und im Plenum des Bundestages erörtert werde. Freilich sei der Bundestag bei seiner Beschlussfassung an die mit seiner Zustimmung zustande gekommenen rechtlichen Festlegungen über den Einsatz bewaffneter Streitkräfte gebunden. Der Zustimmungsvorbehalt für den Einsatz bewaffneter Streitkräfte verleihe dem Bundestag keine Initiativbefugnis; der Bundestag könne einem von der Bundesregierung beabsichtigten Einsatz seine Zustimmung versagen $^{30}$ oder ihn, wenn er ausnahmsweise ohne seine Zustimmung schon begonnen habe, unterbinden, nicht aber die Regierung zu solch einem Einsatz der Streitkräfte verpflichten. Der der Regierung von der Verfassung für außenpolitisches Handeln gewährte Eigenbereich exekutiver Handlungsbefugnis und Verantwortlichkeit werde

27 Bisher einziger offizieller Anwendungsfall der »Gefahr-im-Verzug « - Regelung war die nationale Evakuierungsoperation LIBELLE am 14.03.1997, die das Bundeskabinett an diesem Tage zur Evakuierung deutscher Staatsbürger und unter konsularischer Obhut befindlicher Staatsangehöriger anderer Nationen aus Albanien anordnete und sofort durchführte. Der Deutsche Bundestag wurde um nachträgliche Billigung dieses Einsatzes ersucht. Die hierzu erstellte Entscheidung, nämlich die Zustimmung des Deutschen Bundestages vom 20.03.1997, ist in BT-Drs. 13/7233 vom 18.03.1997 dokumentiert. Vgl. auch: Claus Kreß, Die Rettungsoperation der Bundeswehr in Albanien am 14. März 1997 aus völker- und verfassungsrechtlicher Sicht, ZaöRV 1997, S. 329 ff.; Klaus Dau, Die militärische Evakuierungsoperation »Libelle« - ein Paradigma der Verteidigung? NZWehrr 1998, S. 89 ff.; Willibald Hermsdörfer, Einsatz deutscher Streitkräfte zur Evakuierung deutscher Staatsbürger aus Albanien, Bayerische Verwaltungsblätter (BayVBl.) 1998, S. 652 ff. In einem weiteren Fall wurde nicht so ohne weiteres offensichtlich, ob es sich hier ebenfalls um die Inanspruchnahme von Gefahr im Verzug handelte: Im Falle des IFOR-Einsatzes in Kroatien und zeitlich begrenzt in Bosnien-Herzegowina beschloss die Bundesregierung, bestimmte Kräfte bereitzustellen und sie einzusetzen, »sobald der Friedensvertrag für Bosnien-Herzegowina unterzeichnet ist und ein entsprechendes Mandat des Sicherheitsrats der Vereinten Nationen sowie ein entsprechender Beschluss des NATO-Rats vorliegen.« (BT-Drs. 13/ 3122 vom 28.11.1995, Zustimmung des Deutschen Bundestages am 06.12.1995, Ziffer 1 Abs. 1 und 2). Gemäß Ziffer 3 dieses Beschlusses konnten »Personal und Führungsunterstützungskräfte für internationale Hauptquartiere im früheren Jugoslawien .... bereits verlegt werden, bevor die unter Nummer 1 genannten Voraussetzungen erfüllt sind.«

28 BVerfGE 90, 286 [388].

29 Vgl. Fn. 5.

30 Dies ist bisher erst einmal geschehen: Der erste Antrag der Bundesregierung zur deutschen Beteiligung an der internationalen Sicherheitspräsenz im Kosovo fand im Plenum keine Zustimmung: BT-Drs. 14/1111 vom 07.06.1999, Plenardiskussion am 08.06.1999. Die Bundesregierung musste die Zustimmung zur deutschen Beteiligung an der KFOR-Operation im Kosovo am 11.06.1999 erneut beantragen: BT-Drs. 14/1133 vom 11.06.1999, Zustimmung des Deutschen Bundestages am selben Tage. 
durch den Parlamentsvorbehalt nicht berührt. Dies gelte insbesondere hinsichtlich der Entscheidung über die Modalitäten, den Umfang und die Dauer der Einsätze, die notwendige Koordination in und mit Organen internationaler Organisationen. ${ }^{31}$

\section{Bisheriges Verfahren der Parlamentsbeteiligung}

Die Staatspraxis bei Entscheidungen über Einsätze bewaffneter deutscher Streitkräfte aus der Sicht des Deutschen Bundestages wurde bereits beleuchtet; ${ }^{32}$ in einem anderen Beitrag wurden weitere Details wie eine befristete Zustimmung trotz gegenteiligen Wortlauts des von der Bundesregierung vorgelegten Beschlusses (KFOR) oder Protokollerklärungen der Bundesregierung, die damit auf Wünsche des Parlaments reagiert und die eigenen Entscheidungen relativiert (Enduring Freedom, EU-Opertation Concordia), hingewiesen. ${ }^{33} \mathrm{Zu}$ Recht zeigt Wiefelspütz auf, dass die vermeintlich klaren Vorgaben des Bundesverfassungsgericht zur starren Trennung der Befugnisse von Regierung und Parlament von der Staatspraxis seit 1994 relativiert worden sind. ${ }^{34}$ So trägt die Bundesregierung den Wünschen der Parlamentarier zu Einzelheiten der Einsatzdurchführung durch Protokollerklärungen oder sonstiges Entgegenkommen immer wieder Rechnung.

Bei jedem neuen geplanten Einsatz wird im Bundesministerium der Verteidigung (BMVg) zunächst der Entwurf einer Tischvorlage für das Kabinett als sog. »Doppelkopf«-Vorlage, also als gemeinsame Vorlage des BMVg und des Auswärtigen Amtes für das Kabinett, entwickelt. Diese enthält die Bestandteile Kabinettsbeschluss, Entwurf des Bundestagsbeschlusses sowie den Entwurf für den Sprechzettel des Regierungssprechers. Dabei darf inzwischen als gesichert gelten, dass sog. »reine« Verlängerungsbeschlüsse für einen bereits laufenden Einsatz ziemlich kurz die wesentlichen Eckdaten zur Fortsetzung des Einsatzes darlegen und Bezug auf die bisherigen Beschlüsse zu diesem Einsatz nehmen. ${ }^{35}$ Abänderungen der bestehenden Rah-

31 BVerfGE 90, 286 [389]. Zur weiterführenden Beschäftigung mit dem Grundsatzjudikat vgl. auch Klaus Dau/Gotthard Wöhrmann, Der Auslandseinsatz deutscher Streitkräfte - Eine Dokumentation des AWACS-, des Somalia- und des Adria-Verfahrens vor dem Bundesverfassungsgericht, Heidelberg 1996.

32 Martin Limpert, Auslandseinsatz der Bundeswehr, Berlin 2002, S. 62 ff.

33 Vgl. Dieter Wiefelspütz (Beteiligung, Fn. 1), S. 148 ff.

34 Vgl. Dieter Wiefelspütz (Parl.-vorbehalt - Fn. 1), S. 51; ders.: (Beteiligung, Fn. 1), S. 148; vgl. zu den materiell-rechtlichen Prüfungsschritten bei einer Entscheidung über einen Streitkräfteeinsatz auch Peter Dreist a. a. O. (Fn. 26).

35 Beispiele: Fortsetzung der deutschen Beteiligung an der internationalen Sicherheitspräsenz im Kosovo (KFOR) im Jahre 2000, Kabinettentscheidung vom 24.05.2000, BT-Drs. 14/ 3454 vom 25.05.2000, Zustimmung des Deutschen Bundestages am 08.06.2000; oder: Fortsetzung der Beteiligung bewaffneter deutscher Streitkräfte an dem NATO-geführten Einsatz auf mazedonischem Territorium zum Schutz von Beobachtern internationaler Organisationen (AMBER FOX) im Dezember 2001, BT-Drs. 14/7770 vom 10.12.2001, Zustimmung des Deutschen Bundestages am 13.12.2001. 
menbedingungen sowie neue Einsatzoptionen für einen laufenden Einsatz müssen gesondert dargestellt werden. ${ }^{36}$

Seit der Beschlussfassung zur Beteiligung bewaffneter deutscher Streitkräfte an dem NATO-geführten Einsatz auf mazedonischem Territorium zum Einsammeln und Zerstören der Waffen, die durch die ethnisch albanischen bewaffneten Gruppen freiwillig abgegeben werden, ${ }^{37}$ gibt es ein feststehendes System von 10 bzw. 11 Ziffern für die Formulierung der Bundestagsbeschlüsse (die Anzahl ist von den Besonderheiten des jeweiligen Einsatzes abhängig), in denen die völkerrechtlichen Grundlagen und die politischen Rahmenbedingungen des Einsatzes (1), die verfassungsrechtlichen Grundlagen (2), der Auftrag (3), die besonderen Voraussetzungen dieses konkreten Einsatzes (falls notwendig - 4), sodann die Ermächtigung zum Einsatz sowie Beginn und Dauer (5), die Angaben über die einzusetzenden Kräfte (6), Angaben zu Status und Rechten (7), zum Einsatzgebiet (8), zum Personaleinsatz (9), zur besonderen Auslandsverwendung im Sinne des § 58a Bundesbesoldungsgesetz (BBesG) (10) sowie zur Finanzierung (11) enthalten sind. ${ }^{38}$ Fällt die hier dargestellte Ziffer 4 fort, rücken alle Ziffern ab Ziffer 5 um einen Platz auf. ${ }^{39}$

Ist der Entwurf auf der Arbeitsebene mit allen Abteilungen des BMVg abgestimmt, wird er zunächst in jeder betroffenen Abteilung des BMVg dem Abteilungsleiter oder dem Inspekteur, dann dem Generalinspekteur und schließlich dem zuständigen Staatssekretär und, wenn alle diese Ebenen den Entwurf gebilligt haben sollten, dem Minister vorgelegt. Jede Befassung einer anderen Ebene kann zu Änderungswünschen

36 Beispiele: Fortsetzung der deutschen Beteiligung an der internationalen Sicherheitspräsenz im Kosovo (KFOR) im Jahre 2001 - Erweiterung des Einsatzzwecks auf die Berechtigung zur Durchführung des Militärisch-Technischen Abkommens (MTA) vom 09.06.1999 und hierzu die Erlaubnis, auch in der Bundesrepublik Jugoslawien (heute: Republik Serbien und Montenegro) in der Boden- und Luftsicherheitszone eingesetzt zu werden, BT-Drs. 14/5972 vom 09.05.2001, Zustimmung des Deutschen Bundestages am 01.06.2001; oder: Fortsetzung der Beteiligung bewaffneter deutscher Streitkräfte an dem Einsatz einer internationalen Sicherheitsunterstützungstruppe in Afghanistan im Dezember 2002, dabei Erweiterung des Personalumfangs von 1500 auf 2500 Soldaten wegen der gemeinsam mit den Niederlanden zu übernehmenden Lead-Nation-Funktion, BT-Drs. 15/128 vom 03.12.2002, Zustimmung des Deutschen Bundestages am 20.12.2002.

37 BT-Drs. 14/6830 vom 23.08.2001, Zustimmung des Deutschen Bundestages am 29.08.2001.

38 Kapitän zur See Karl-Wilhelm Bollow und Kapitän zur See Berend Burwitz gebührt der Dank für ihre wertvolle Anregungen zu diesem Aufbau.

39 Beispiele für Bundestagsbeschlüsse, bei denen seither in 10 operativen Ziffern (Ziffer 4 ist in diesen Fällen bereits die Regelung der Ermächtigung zum Einsatz, Beginn und Dauer) die Details des Einsatzes erläutert werden: Erste Zustimmung zur Beteiligung bewaffneter deutscher Streitkräfte an dem NATO-geführten Einsatz auf mazedonischem Territorium zum Schutz von Beobachtern internationaler Organisationen im Rahmen der weiteren Implementierung des politischen Rahmenabkommens vom 13. August 2001 (AMBER FOX), BT-Drs. 14/6970 vom 27.09.2001, Zustimmung des Deutschen Bundestages am selben Tage; Kabinettsbeschluss zur deutschen Beteiligung an ENDURING FREEDOM, BTDrs. 14/7296 vom 07.11.2001, Zustimmung des Deutschen Bundestages am 16.11.2001; Kabinettsbeschluss zur deutschen Beteiligung an der internationalen Sicherheitsunterstützungstruppe in Afghanistan (ISAF), BT-Drs. 14/7930 vom 21.12.2001, Zustimmung des Deutschen Bundestages am 22.12.2001. Vgl. ferner die Darstellung bei Dieter Wiefelspütz (Parl.-vorbehalt - Fn. 1), S. 44 ff. 
führen. Fast gleichzeitig muss auf der untersten Arbeitsebene (Referatsleiter) auch die Beteiligung der anderen zu beteiligenden Ressorts (immer: Auswärtiges Amt, BMJ, BMI, Bundeskanzleramt, BMF, von Fall zu Fall auch andere wie BMWA, BMZ oder BMVBW) sichergestellt werden. Schließlich wird in einer Konferenz mit den beteiligten Ressorts auf Arbeitsebene eine Endfassung hergestellt, die dem Bundesminister des Auswärtigen und der Verteidigung zur Unterzeichnung vorgelegt werden.

Sodann wird dem Deutschen Bundestag der Entwurf eines Beschlussvorschlages und eine Beschlussempfehlung zur Herbeiführung der Zustimmung des Deutschen Bundestages zugeleitet. Hieraus fertigt die Druckerei eine Bundestagsdrucksache mit laufender Nummerierung, die sodann den Abgeordneten für die sog. »erste « Lesung im Plenum übermittelt wird. Diese erste Lesung wird oft auch zumindest zu einer kurzen, etwa 30-minütigen Aussprache genutzt.

Nach der ersten Lesung terminieren die Fachausschüsse die Besprechung und Abstimmung über den konkreten Einsatzbeschluss (Entwurf) als Tagesordnungspunkt ihrer nächsten oder einer ihrer nächsten Sitzungen, nachdem der Beschlussentwurf diesen Ausschüssen als Bundestagsdrucksache zugeleitet wurde. Federführend ist bei Einsatzbeschlüssen der Auswärtige Ausschuss, beteiligt sind ferner immer der Verteidigungsausschuss, der Rechtsausschuss, der Ausschuss für Menschenrechte und humanitäre Hilfe, der Ausschuss für wirtschaftliche Zusammenarbeit und Entwicklung und bei Angelegenheiten der Europäische Union (EU) auch der Ausschuss für diese Angelegenheiten. Außerdem wird gemäß $§ 96$ der Geschäftsordnung des Bundestages immer der Haushaltsausschuss beteiligt; dieser stellt in einer gesonderten Drucksache, die dem Plenum ebenfalls zugeleitet wird, fest, ob die vorgeschlagene Entscheidung, die ja immer auch erhebliche Beträge aus dem Bundeshaushalt verlangt, mit der Haushaltslage des Bundes vereinbar ist. ${ }^{40}$

Die Ergebnisse und Empfehlungen der beteiligten Fachausschüsse werden dem federführenden Auswärtigen Ausschuss (Ausnahme: Haushaltsausschuss) übermittelt, der die Ergebnisse zusammenfasst und dem Plenum diese Zusammenfassung zusammen mit einer Mitteilung über sein eigenes Votum, ggfls. auch über weitere mitteilenswerte Punkte übermittelt. Im Plenum findet sodann die zweite und dritte Lesung einschließlich erneuter Aussprache - und schließlich die namentliche Abstimmung über den konkreten Einsatz statt.

Besonders interessant bei Einsatzentscheidungen sind überraschende Entwicklungen im parlamentarischen Raum, mit denen man vorher so nicht rechnen konnte. Diese Seite der Entscheidungsfindung wird bei Limpert eindrucksvoll dargestellt. ${ }^{41}$ Dabei wirft er einen außerordentlich aufschlussreichen Blick auf die Vorgänge im par-

40 Vgl. z. B. den Bericht des Haushaltsausschusses zur Beteiligung bewaffneter deutscher Streitkräfte an dem EU-geführten Einsatz auf mazedonischem Territorium zur weiteren Stabilisierung des Friedensprozesses und zum Schutz von Beobachtern internationaler Organisationen im Rahmen der weiteren Implementierung des politischen Rahmenabkommens vom 13. August 2001 (Operation CONCORDIA), BT-Drs. 15/710 vom 20.03.2003, oder an dem EU-geführten Einsatz zur Stabilisierung der Sicherheitslage und Verbesserung der humanitären Situation in Bunia, BT-Drs. 15/1177 vom 18.06.2003.

41 Martin Limpert a. a. O. (Fn. 32), S. 62 ff., insbesondere S. 82 ff. 
lamentarischen Raum bei der Vorbereitung der Entscheidung zur deutschen Beteiligung an der US-geführten Operation ENDURING FREEDOM zur Bekämpfung des internationalen Terrorismus. ${ }^{42}$ Hier ist auch dargelegt, dass insgesamt 94 Abgeordnete mündliche oder schriftliche Erklärungen zur Abstimmung über diesen Antrag der Bundesregierung abgaben, was zeigt, dass sich die Abgeordneten diese Entscheidung wirklich nicht leicht gemacht haben. ${ }^{43}$ Nunmehr soll dargelegt werden, welche Fragen immer wieder in den Ausschüssen und bei der parlamentarischen Diskussion bei Einsatzentscheidungen thematisiert werden.

\section{Offene Fragen im parlamentarischen Raum}

\section{a. Einsatz bewaffneter Streitkräfte}

Der Begriff des Einsatzes bewaffneter Streitkräfte wird im Urteil des Bundesverfassungsgerichts nicht näher erläutert oder definiert, sondern vorausgesetzt. Gegenstand der Urteilsfindung war, wie bereits dargelegt, die deutsche Beteiligung an den Operationen UNOSOM II in Somalia, SHARP GUARD durch die Flotten von NATO und WEU in der Adria sowie DENY FLIGHT zur Durchsetzung eines Flugverbots über BosnienHerzegowina. Da das Urteil nicht danach differenziert, ob nur große Truppenkontingente oder auch einzelne Soldaten das Merkmal des Einsatzes bewaffneter Streitkräfte erfüllen, und es ferner nicht zwischen Vorbereitungs- und Durchführungsphase eines Einsatzes bewaffneter Streitkräfte unterscheidet und da die Anregung des Bundesverfassungsgerichts, die Einzelheiten des parlamentarischen Beteiligungsverfahrens insbesondere bei Einsätzen, die keinen Aufschub dulden oder erkennbar von geringer Bedeutung sind, in einem Gesetz insbesondere nach Art und Wichtigkeit des Einsatzes sowie Grad der Integration in einem Bündnis näher abzustufen, ${ }^{44}$ von Bundesregierung und Parlament bisher nicht umgesetzt worden ist, muss die Bundesregierung mangels deutlicherer Hinweise bis zu einer Neuregelung davon ausgehen, dass auch die Teilnahme einzelner oder einer geringen Anzahl deutscher Soldaten (z. B. bei Partnership Exchange Programmes $=(\mathrm{PEP})$-Austauschprogrammen, Fact Finding Teams, Erkundungskommandos, Vorkommandos, Hauptquartierpersonal, Unterstützungskräften wie bei den Einsätzen IFOR, AFOR, INTERFET, ISAF) an einem Einsatz bewaffneter Streitkräfte der grundsätzlich vorherigen konstitutiven Zustimmung des Deutschen Bundestages bedarf. ${ }^{45}$ Nicht als Teilnahme an einem Einsatz bewaffneter Streitkräfte konzipiert ist die Entsendung eines in Zivil und unbewaffnet agierenden Krisenunterstützungsteams (KUT) zur Beratung einer Botschaft bei der Eventualfallplanung.

Außerdem geht das Urteil erkennbar davon aus, dass - bis zu einer gesetzlichen Regelung der Details der Zusammenarbeit zwischen Bundestag und Bundesregierung auf Seiten der Exekutive nur die Bundesregierung als Kollegialorgan und auf Seiten des Parlaments nur das Plenum des Deutschen Bundestages wirklich ermächtigt sind, an

42 Vgl. Fn. 41.

43 Martin Limpert a. a. O. (Fn. 32), S. 86 ff.

44 BVerfGE 90, 286 [389].

45 Vgl. auch Peter Dreist a. a. O. (Fn. 1), S. 143 ff.; ders. (Fn. 26), S. 156. 
einem Beschluss über die Beteiligung mit deutschen Soldaten an einem Einsatz bewaffneter Streitkräfte als Entscheidungsträger mitzuwirken. Zusätzlich sollen, wenn irgend möglich, die Fachausschüsse des Deutschen Bundestages vor einer Entscheidung im Plenum mit dem geplanten Einsatz befasst werden. ${ }^{46}$ Nicht Gegenstand der konstitutiven Zustimmung des Bundestages zu einem Einsatz bewaffneter deutscher Streitkräfte ist die Beteiligung von Beamten der Polizei, des BGS oder anderer Bundes- oder Länderbehörden oder die Beteiligung von Zivilpersonen an einem solchen Einsatz. Bisher ist jedoch nicht hinreichend geklärt, was der Begriff »Einsatz bewaffneter Streitkräfte« im Sinne des Grundsatzjudikats vom 12. Juli 1994 wirklich bedeutet. ${ }^{47}$

$\mathrm{Zu}$ einer Klärung hat auch die Eilentscheidung im jüngsten AWACS-Rechtsstreit vor dem Bundesverfassungsgericht wegen des AWACS-Einsatzes des NATO-E3-A-Verbandes in der Türkei während der US-geführten Operation Iraqi Freedom ohne Bundestagsbeschluss bisher nicht endgültig beigetragen; denn das Gericht hat in der Sache nicht entschieden, sondern lediglich dem Hauptsacheverfahren ausdrücklich die Klärung der Frage vorbehalten, wie weit der konstitutive Parlamentsvorbehalt im Wehrverfassungsrecht wirklich reiche. Dieser sei auf das historische Bild eines Kriegseintritts zugeschnitten; tatsächlich würden heute aber Kriege nicht mehr förmlich erklärt; eine sukzessive Verstrickung in bewaffnete Auseinandersetzungen stehe dem offiziellen Kriegseintritt gleich. ${ }^{48}$ Deshalb unterliege grundsätzlich jeder Einsatz bewaffneter deutscher Streitkräfte der konstitutiven parlamentarischen Mitwirkung. Diese Hinweise sind Signale für ein modifiziertes Verständnis des Begriffs »Einsatz bewaffneter Streitkräfte«, die in einem Parlamentsbeteiligungsgesetz berücksichtigt werden könnten.

Im Hauptsacheverfahren sei deshalb der Frage nachzugehen, wann ein »Einsatz bewaffneter Streitkräfte « anzunehmen sei, insbesondere wann deutsche Soldaten in »bewaffnete Unternehmungen einbezogen« seien. Für den konkreten Fall sei zu klären, ab wann und in wieweit ein Einsatz in integrierten NATO-Verbänden zu einem den Parlamentsvorbehalt auslösenden bewaffneten Einsatz werde, wenn diese Verbände den Luftraum eines Bündnismitgliedes überwachten, dessen Staatsgebiet unmittelbar an ein kriegsbefangenes Territorium angrenze, oder wenn sich die Überwachung darüber hinaus auf das Territorium eines an dem Konflikt beteiligten Staates erstrecke. Klärungsbedürftig könne ferner sein, inwieweit auch eine mittelbare Einbeziehung in bewaffnete Unternehmungen den Parlamentsvorbehalt auslöse. Dies gelte insbesondere im vorliegenden Fall, wenn Entwicklungen möglich seien, dass der Bündnispartner, dessen Gebiet zu sichern sei, selbst zu einer kriegführenden Partei werde. ${ }^{49}$ Bei diesem Ansatz besteht allerdings die Gefahr, unklare Rechtsbegriffe wie mittelbare und unmittelbare Einbeziehung in bewaffnete Unternehmungen aufgrund ständig neuer Entwicklungen im Rahmen einer stets ergänzungsbedürftigen Kasuistik

46 BVerfGE 90, 286 [387 - 390].

47 Dieter Wiefelspütz (Parl.-vorbehalt - Fn. 1), S. 31 ff.; ders.: (Beteiligung, Fn. 1), S. 137 - 146.

48 Entscheidung des Bundesverfassungsgerichts im Verfahren 2 BvQ 18/03 vom 25.03.2003, auch verfügbar auf der Homepage des Bundesverfassungsgerichts: http://www.bundesverfassungsgericht.de, Menüpunkt Entscheidungen, Jahrgang 2003, Monat März, Tagesziffer 25. Vgl. Dieter Wiefelspütz (Parl.-vorbehalt - Fn. 1), S. 36. 
immer wieder ergänzen zu müssen; denn nach aller Erfahrung ist jeder Einsatz singulär, der nächste Einsatz weist Abweichungen von allen bisherigen Einsätzen auf. Vorzuziehen wäre statt dessen eine abstrakt-generelle Lösung, mit der bestimmte Einsätze - im Rahmen der Vorgaben des Grundsatzjudikats vom 12. Juli 1994 - als nicht zustimmungspflichtig oder als von vorneherein gebilligt festgelegt werden könnten; dies vergrößerte den Handlungsspielraum der Bundesregierung und ließe künftig Kleinsteinsätze $\mathrm{zu}$, die bisher in einem weder geregelten noch anerkannten Verfahren mit den Obleuten und Fraktionsvorsitzenden abgesprochen werden oder gar nicht stattfinden, weil die Bundesregierung für einen oder wenige Soldaten nicht das dargelegte umfangreiche Procedere im Deutschen Bundestag durchführen will.

Fest steht bisher, dass als Einsatz bewaffneter Streitkräfte die im Grundgesetz selbst geregelten Einsätze nach Art. 115a GG (Verteidigungsfall), Art. 80a GG (besondere Feststellung zum Einsatz der Streitkräfte im Spannungsfall), Art. 87a Abs. 3 GG (Objektschutz und Verkehrsregelung im Verteidigungs- und Spannungsfall), Art. 87a Abs. 4 GG (Objektschutz und Bekämpfung organisierter und militärisch bewaffneter Aufständischer), Art. 35 Abs. 2 Satz 2 GG (regionaler Katastrophennotstand). Art. 35 Abs. 3 GG (überregionaler Katastrophennotstand) sowie Art. 87a Abs. 2 GG (zur Verteidigung) anzusehen sind. Fest steht ferner, dass der konkrete Einsatz in einem Bündnisfall (Enduring Freedom), der Einsatz im Rahmen von Friedensmissionen der VN sowie Einsätze, bei denen die Soldaten der Bundeswehr sonst in bewaffnete Unternehmungen einbezogen sind, was in einer Prognoseentscheidung nach dem Grad der Wahrscheinlichkeit vor Einsatzbeginn zu entscheiden ist, als Einsätze bewaffneter Streitkräfte gelten. Dem könnte künftig die sukzessive Verstrickung in bewaffnete Auseinandersetzungen, zumal bei grenznahen Aktionen zu einer Kriegspartei oder bei der Überwachung dieser Partei, gleichstehen.

Das entscheidende allgemeine Kriterium dürfte nach alldem der Grad der Gefahr der Einbeziehung deutscher Soldaten in bewaffnete Unternehmungen, in eine bewaffnete Auseinandersetzung sein, in der sich ein militärtypisches und damit staatsrechtlich relevantes Kriegsrisiko oder - in Friedensmissionen - das Risiko bewaffneter Auseinandersetzungen von einigem Gewicht verwirklicht. Auch die Zahl der eingesetzten Soldaten (z. B. bei Austauschprogrammen der Einsatz eines einzelnen deutschen Soldaten auf einem US-Raketenkreuzer, ${ }^{50}$ einiger Soldaten als Fact Finding Teams oder Erkundungskommandos zu Beginn eines neuen Einsatzes oder als sonstiges HQ- oder Unterstützungspersonal) ist nicht allein entscheidend, sondern das zuvor genannte Kriterium. Denn auch ein einzelner Soldat kann sich im Funktionsdienst auf einem Kriegsschiff oder als Pilot in effektiver und damit die Bundesrepublik auch in einen konkreten Konflikt verstrickender Weise an einer bewaffneten Unternehmung beteiligen. ${ }^{51}$ Deshalb und wegen der bestehenden erheblichen Abgrenzungsschwierigkeiten könnte man in einem Parlamentsbeteiligungsgesetz versuchen, den Begriff des Einsatzes bewaffneter Streitkräfte relativ allgemein zu lassen und eine Abstufung des Parlamentsvorbehalts durch unterschiedliche Beteiligungsformen - abhängig von dem

50 Meldung des »STERN«, Ausgabe 17/1999 vom 22.04.1999, S. 34.

51 Vgl. Fn. 50; a. A. Dieter Wiefelspütz (Beteiligung, Fn. 1), S. $139-141$. 
Grad der Gefahr einer Einbeziehung in kriegerische oder ähnliche Akte - durch prozedurale Faktoren $\mathrm{zu}$ erreichen, andererseits aber bestimmte Einsatzformen, die die beschriebene Schwelle nicht erreichen, vom Einsatzbegriff auszunehmen.

\section{b. Rückholrecht?}

Trotz der insoweit eindeutigen Vorgaben des Bundesverfassungsgerichts wird im Deutschen Bundestag sowohl im Plenum als auch in den Fachausschüssen immer wieder darüber diskutiert, ob bereits nach geltender Rechtslage dem Parlament ein sog. »Rückholrecht«, also ein Recht zur Beendigung eines Einsatzes zusteht. Dabei reklamieren einige das Bestehen eines generellen Rückholrechts, ${ }^{52}$ andere bezweifeln dessen Existenz. ${ }^{53}$ Die Befürworter eines parlamentarischen Rückholrechts bei einem Einsatz bewaffneter deutscher Streitkräfte, dem das Parlament bereits zugestimmt hat, tragen vor, ein Rückholrecht des Parlaments müsse bestehen, weil dies auch in anderen Fällen, z. B. bei der Beendigung des Verteidigungsfalles nach Art. 1151 Abs. 2 GG, vorgesehen sei; dies müsse bei anderen Einsätzen bewaffneter deutscher Streitkräfte ebenfalls gelten. ${ }^{54}$

Auch wenn hier der Raum für eine vertiefte Auseinandersetzung mit dieser Rechtsfrage fehlt, muss doch der Hinweis erlaubt sein, dass ein Rückrufrecht für eingesetzte Streitkräfte im Art. 1151 Abs. 2 GG sowie im Art. 87a Abs. 4 Satz 2 GG ausdrücklich vorgesehen ist. Dem gegenüber konstituiert das Urteil des Bundesverfassungsgerichts für Auslandseinsätze gar kein Rückrufrecht, sondern nur für den Fall, dass ein Einsatz wegen Gefahr im Verzuge von der Bundesregierung ausnahmsweise ohne vorherige Zustimmung des Bundestages beschlossen und begonnen wurde, entweder die Möglichkeit, diese bisher fehlende Zustimmung nachzuholen oder den Einsatz durch Verweigerung der erbetenen Zustimmung zu unterbinden, wobei dann die Regierung die Weisungen erteilen muss, mit denen die Streitkräfte unverzüglich zurückgeholt werden. ${ }^{55}$ Für den Regelfall, dass die vorherige Zustimmung des Parlaments zu einem konkreten Einsatz bereits erteilt wurde, billigt das Judikat dem Parlament gerade keine Initiativbefugnis und damit auch kein Rückholrecht zu. ${ }^{56}$ Ein allgemeines Rückholrecht,

52 MdB Christine Lambrecht (SPD) bezeichnet die Frage als nicht abschließend geklärt; MdB Christian Schmidt (CDU/CSU) bezeichnet sie als umstritten. Die herrschende Meinung allerdings sage Nein! Dem pflichtet MdB Jörg van Essen bei, Deutscher Bundestag, Plenarprotokoll 15/10, 10. Sitzung des Deutschen Bundestages vom 14.11.2002, S. 634 (D). Vgl. ferner Konrad Hummel, Rückrufrecht des Bundestages bei Auslandseinsätzen der Streitkräfte, NZWehrr 2001, S. 221 ff. [226].

53 Peter Dreist a. a. O. (Fn. 1), S. $147 \mathrm{ff}$.

54 Konrad Hummel, Rückrufrecht des Bundestages bei Auslandseinsätzen der Streitkräfte, NZWehrr 2001, S. 221 ff. [226]; Dieter Wiefelspütz (Beteiligung, Fn. 1), S. 151; Georg Nolte, a. a. O. (Fn. 6), S. 681; Michael Wild a. a. O. (Fn. 7), S. 630; Christian Burkiczak a. a. O. (Fn. 7), S. 86. Vgl. ferner Christian Fischer u. Andreas Fischer-Lescano, Enduring Freedom für Entsendebeschlüsse? Völker- und verfassungsrechtliche Probleme der deutschen Beteiligung an Maßnahmen gegen den Internationalen Terrorismus, Kritische Vierteljahresschrift für Gesetzgebung und Rechtswissenschaft (KritV) 2002, S. 113 ff. [127 - 129].

55 BVerfGE 90, 286 [388].

56 BVerfGE 90, 286 [389]: »Der Zustimmungsvorbehalt für den Einsatz bewaffneter Streitkräfte verleiht dem Bundestag keine Initiativbefugnis.« Vgl. auch Peter Dreist a. a. O. (Fn. 1), S. 148/149. 
das sich als Ausübung einer eigenen Initiativbefugnis darstellt, steht dem Parlament mithin gegenwärtig nicht zu.

Dies verkennen die o. a. Autoren, die argumentativ aus den im Grundgesetz bei einzelnen Einsatzoptionen vorhandenen Rückrufmodalitäten ableiten, ein solches Recht stehe dem Bundestag immer zu. ${ }^{57}$ Demgegenüber zeichnet das Grundgesetz ein differenziertes Bild: Die Aufhebung bestimmter Maßnahmen einschließlich des Streitkräfteeinsatzes ist dem Deutschen Bundestag lediglich in den Fällen des Art. 80a Abs. 2 und Abs. 3 GG, 87a Abs. 4 GG sowie 1151 Abs. 2 Satz 1 GG übertragen. Für den Fall des Art. 35 Abs. 3 GG hat lediglich der Bundesrat allein die Befugnis, die Einstellung der Maßnahmen einschließlich des Streitkräfteeinsatzes zu verlangen. Zudem kann der Bundesrat alternativ zum Bundestag im Fall des Art. 87a Abs. 4 GG oder zusätzlich im Fall des Art. 1151 Abs. 2 Satz 2 GG die Beendigung des Streitkräfteeinsatzes im Verteidigungsfall verlangen.

In den Fällen des Art. 87a Abs. 2 GG (Einsatz zur Verteidigung), 87a Abs. 3 GG (zum Objektschutz und zur Verkehrsregelung) und Art. 35 Abs. 2 und 3 GG und außerdem im Fall des Einsatzes der Streitkräfte im Ausland nach Art. 24 Abs. 2 GG fehlt jedoch eine Regelung, die dem Deutschen Bundestag entweder auf der Basis des Grundgesetzes oder nach Verfassungsrichterrecht ein Revokationsrecht für einen einmal beschlossenen Einsatz zubilligte. Damit sieht deutsches Verfassungsrecht die Entscheidung über die Beendigung eines konkreten Streitkräfteeinsatzes nur ausnahmsweise als Befugnis des Parlaments, in der Mehrzahl der Fälle als Handlungsprärogative der Exekutive an.

Für die Einführung eines solchen Revokationsrechts jenseits der vom Bundesverfassungsgericht im Wege des Verfassungsrichterrechts bisher verfassten Regelungen wird teilweise eine Verfassungsänderung gefordert. Ein solches neues und bisher im Ergebnis nicht bestehendes Parlamentsrecht ${ }^{58}$ wird teilweise unter Hinweis auf die Rechtslage in den USA als die verfassungspolitisch, sicherheitspolitisch und verfassungsrechtlich allerbeste, sauberste Lösung angesehen. ${ }^{59}$ Jedenfalls sei es für die Zukunft sinnvoll und unverzichtbar, weil das Parlament handlungsfähig sein müsse, wenn die Bewertung eines konkreten Einsatzes sich entgegen der ursprünglichen Zustimmung des Bundestages nach ein bis zwei Jahren anders als erwartet entwickle. ${ }^{60}$ Andere sehen dieses Rückholrecht sogar als bereits existent, aber als »stumpfes Schwert« an, weil es gegenüber der amtierenden Regierung eine derart verletzende Wirkung habe, dass es bei Gebrauch die Regierung selbst in Frage stelle. ${ }^{61}$ Diese Position wird modifiziert mit dem Hinweis, das Rückholrecht könne auch als Ersatz für eine Entsendeentscheidung des Bundestages verstanden werden; dies reiche zur Wahrung der Parlamentsrechte überhaupt nicht aus. ${ }^{62}$ Soweit jedoch weder das Grundge-

57 Vgl. Fn. 54

58 DVParl-Protokoll vom 04.06.2003, dort Prof. Josef Isensee, S. 29.

59 DVParl-Protokoll vom 04.06.2003, dort Prof. Rupert Scholz, S. 8 u. 9 sowie S. 40.

60 DVParl-Protokoll vom 04.06.2003, dort Dieter Wiefelspütz, S. 37/38; ders.: (Parl.-vorbehalt - Fn. 1), S. 66 f.

61 DVParl-Protokoll vom 04.06.2003, dort Ronald Pofalla, S. 28.

62 DVParl-Protokoll vom 04.06.2003, dort Ronald Pofalla, S. 47. 
setz noch eine Entscheidungen des Bundesverfassungsgerichts eine Vorgabe als geltendes Verfassungsrecht normieren, bestehen Spielräume: So könnte es sich empfehlen, statt eines allgemeinen und umfassenden Rückholrechts dem Parlament ein solches Recht für den Fall zuzubilligen, dass sich wesentliche Grundannahmen für einen bereits laufenden Einsatz nach einiger Zeit ändern (Argument der clausula rebus sic stantibus). Für diesen Fall wäre ein Rückholrecht sinnvoll und könnte in einem Gesetz verabredet werden (volenti non fit iniuria). Dies käme insbesondere bei unbegrenzt gebilligten Einsätzen in Betracht, ${ }^{63}$ wobei sich neben einem erst noch neu zu schaffenden Rückruf- oder Revokationsrecht des Bundestages inzwischen auch die Möglichkeit der Protokollerklärung der Bundesregierung mit der Zusicherung einer erneuten konstitutiven Zustimmung alle 12 Monate etabliert hat. ${ }^{64}$

Dieser Fall eines jahrelang laufenden Einsatzes mit plötzlich auftretenden grundlegenden Änderungen zwänge die Bundesregierung ohnehin zu einer Überprüfung ihrer bisherigen Entscheidung; deshalb könnte sich für diesen Fall ebenso die Regelung eines bisher nicht gegebenen Revokationsrechts für den Deutschen Bundestag anbieten. Diese Idee könnte mit einem Hinweis auf Art. 115l Abs. 2 Satz 3 GG unterstützt werden: Danach ist der Verteidigungsfall unverzüglich für beendet zu erklären, wenn die Voraussetzungen für seine Feststellung nicht mehr gegeben sind. Sind demnach die Voraussetzungen, unter denen eine Entscheidung getroffen wurde, nicht mehr gegeben, muss eine Entscheidung getroffen werden, die der neuen Lage entspricht. In diesem Fall wäre ein Revokationsrecht sinnvoll und möglich.

\section{c. »Vorratsbeschluss und Parlamentsheer}

Gerade im Zusammenhang mit der jüngsten Entscheidung des Deutschen Bundestages zur Verlängerung und Modifizierung seiner Zustimmung zur deutschen Beteiligung an Enduring Freedom ${ }^{65}$ sind wieder einmal Stimmen laut geworden, der Beschluss enthalte ein zu weit gefasstes Einsatzgebiet und das Parlament solle den Einsatz eines so großen Kontingents (3100 Soldaten) billigen, obwohl derzeit nur mit dem Einsatz von ca. 700 Soldaten gerechnet werde. ${ }^{66}$ Aus rechtlicher Sicht wird mit dem Hinweis auf den Charakter eines Vorratsbeschlusses die Einhaltung der Vorgabe des Bundesverfassungsgerichts eingefordert, der konkrete Einsatz bedürfe der grundsätzlich vorherigen konstitutiven Zustimmung des Deutschen Bundestages. ${ }^{67}$

63 BT-Drs. 13/10977 vom 17.06.1998, Zustimmung des Deutschen Bundestages am 19.06.1998 (SFOR- II, Ziffer 4 - gilt seitdem unverändert); BT-Drs. 15/696 vom 19.03.2003, Zustimmung des Deutschen Bundestages am 20.03.2003 (EU-Operation Concordia in Mazedonien - Ziffer 4 Abs. 2); vgl. ferner die Beschlüsse zum Einsatz der internationalen Sicherheitspräsenz im Kosovo seit dem Jahre 2000, die ebenfalls mit der sog. »SFOR «-Formel versehen sind, aufgrund einer Protokollerklärung der Bundesregierung jedoch alle 12 Monate auf Antrag einer Fraktion erneut konstitutiv bestätigt werden.

64 Vgl. Peter Dreist, Rechtliche Aspekte des KFOR-Einsatzes, NZWehrr 2001, S. 1 ff. [10, 11].

65 Vgl. Fn. 23 am Ende.

66 Vorabveröffentlichung des Plenarprotokolls der 73. Sitzung des Deutschen Bundestages in der 15. Legislaturperiode, 07.11.2003, abrufbar auch im Internet unter http://www.bundestag.de, Menüpunkt »Plenarprotokolle«, Datum.

67 BVerfGE 90, 286 [387]. 
Hierbei rügen die Abgeordneten immer wieder Details des von der Bundesregierung vorgelegten Zustimmungsantrages, weil sie nicht genau genug seien oder der Bundesregierung zu viele Spielräume bei der Einsatzdurchführung einräumten, ohne dass dies sachlich geboten sei. Im Ergebnis wird die verfassungsrechtliche Zulässigkeit eines solchen Antrages wegen einiger den Abgeordneten nicht genau genug erscheinenden Bestandteile in Frage gestellt, ohne dass der Deutsche Bundestag in seiner Gesamtheit dabei die verfassungsrechtlichen Vorgaben mit einbezieht: Denn das Judikat vom 12. Juli 1994 gibt den Wortlaut des von der Bundesregierung vorzulegenden Zustimmungsantrages nicht vor. Es enthält jedoch eine Passage, die der Bundesregierung in Zusammenhang mit der Darlegung, dem Bundestag stehe kein eigenes Initiativrecht $\mathrm{zu}$, ausdrücklich darauf verweist, dass als Kernbereich der exekutiven Eigenverantwortung insbesondere die Entscheidung über die Modalitäten, den Umfang und die Dauer der Einsätze anzusehen sei. ${ }^{68}$

Obwohl die Staatspraxis eine Form von Bundestagsbeschlüssen mit einer klaren Gliederung und zahlreichen Detailangaben ${ }^{69}$ in einer bestimmten Gliederung entwickelt hat und dieses System grundsätzlich nach den Erfahrungen mit inzwischen über 30 Bundestagsbeschlüssen ${ }^{70}$ als bewährt anzusehen ist, muss angesichts der gemäß $\S$ 31 Abs. 1 des Bundesverfassungsgerichtsgesetzes sowohl die Verfassungsorgane des Bundes und der Länder als auch alle Gerichte und Behörden bindenden Feststellungen des Bundesverfassungsgerichts die ausschließliche Zuständigkeit der Bundesregierung für die Durchführung, also das »wie« des Einsatzes, hervorgehoben werden. Demgegenüber erfasst der wehrverfassungsrechtliche Parlamentsvorbehalt lediglich das »ob« des Einsatzes, Vorgaben für die inhaltliche Ausgestaltung eines Antrags der Bundesregierung auf Zustimmung zu einem konkreten Einsatz gibt es nur in einer Hinsicht: Es muss sich um einen bestimmten Einsatz handeln.

Damit steht fest, dass je nach den operativen Bedürfnissen eines bestimmten Einsatzes die Benennung des Staatsgebiets, auf dem der Einsatz stattfindet, die Möglichkeit, angrenzende Territorien für die Zwecke Zugang und Versorgung zu nutzen, ebenso ausreichend ist wie die notwendiger Weise weite Fassung des Einsatzgebiets im Rahmen der Operation Enduring Freedom. ${ }^{71}$ Da die Bundesregierung sich im Fall Enduring Freedom zusätzlich mit einer Protokollerklärung gegenüber dem Parlament dahin gebunden hat, dass nicht beabsichtigt ist, in Ländern außerhalb Afghanistans, in denen es derzeit keine Regierung gibt, deutsche bewaffnete Streitkräfte ohne Befassung des Deutschen Bundestages einzusetzen, den Bundestag kontinuierlich zu unterrichten

68 Vgl. Fn. 31.

69 Vgl. Fn. 37- 39.

70 Beginnend mit dem Nachholbeschluss zur deutschen Beteiligung an SHARP GUARD und DENY FLIGHT (BT-Drs. 12/8303 vom 19.07.1994) sind in der 13. Legislaturperiode weitere 7 Bundestagsbeschlüsse, in der 14. Legislaturperiode weitere 17 Bundestagsbeschlüsse und in der laufenden 15. Legislaturperiode nochmals 8 weitere Entscheidungen durch den Deutschen Bundestag konstitutiv gebilligt worden. Damit ist der Deutsche Bundestag seit dem Grundsatzurteil bis heute (20.11.2003) insgesamt 33 mal konstitutiv mit einem Auslandseinsatz bewaffneter deutscher Streitkräfte befasst worden.

71 Fischer/Fischer-Lescano a. a. O. (Fn. 54), S. 122 - 124. 
und im Falle wesentlicher Abweichungen der zahlenmäßigen Aufgliederung der eingesetzten bewaffneten deutschen Kräfte den Bundestag zu konsultieren, ${ }^{72}$ und die Bundesregierung diese Haltung in einer weiteren Protokollerklärung vom 12.11.2003 nochmals wiederholt und bestärkt hat, ${ }^{73}$ kann hier der Vorwurf eines »Vorratsbeschlusses « in dem Sinne, die Angaben ließen die Zuordnung zu einer bestimmten Operation nicht $\mathrm{zu}$, wirklich nicht greifen. Im Übrigen sei erwähnt, dass vor dem Grundsatzurteil bereits einmal ein Beschluss zu einem Einsatz bewaffneter deutscher Streitkräfte gefasst wurde, der durch seine Schlichtheit ebenso wie durch seine Präzision besticht. ${ }^{74}$ Wollte man den Minimalismus dieser Formulierung auf die Spitze treiben, könnte heute ein entsprechender Beschlussvorschlag lauten: »Der Deutsche Bundestag stimmt der Entscheidung der Bundesregierung vom ........ zu, bewaffnete deutsche Streitkräfte in B-Land zur (es folgt eine Beschreibung des Einsatzzwecks; Alternativen: Unterstützung der Vereinten Nationen, Terrorismusbekämpfung, Unterstützung der KFOR-Operation) einzusetzen.« Der Umstand, dass sich eine andere Staatspraxis in einem langen Prozess des Miteinanders zwischen den beteiligten Verfassungsorganen herausgebildet hat, sollte den Blick auf das verfassungsrechtlich notwendige Mindestmaß nicht verstellen.

\section{d. Geheimhaltung und kontinuierliche Unterrichtung - auch über Spezialkräfte}

Während die Bundesregierung inzwischen seit Jahren ein System der kontinuierlichen Unterrichtung des Parlaments mit schriftlichen Berichten über die Einsatzgebiete etabliert hat, sind zwei Fragen bis heute nicht endgültig geklärt: Wie weit geht die Geheimhaltungsbedürftigkeit bestimmter Einsätze - etwa der Spezialkräfte oder in einem besonderen Fall wie der Operation LIBELLE - vor dem und während des Einsatzes und wie kann das Parlament möglichst zeitnah unterrichtet werden? Dabei ist grundsätzlich anerkannt, dass bestimmte Einsätze als Ganzes oder bestimmte Teilaspekte geheimhaltungsbedürftig sind und nicht in einer parlamentarischen Debatte öffentlich diskutiert werden können und dürfen, um den Zweck der geplanten oder laufenden Operation nicht zu gefährden und auch, um die im Einsatz engagierten Soldaten zu schützen. ${ }^{75}$

72 Beschlussempfehlung des federführenden Auswärtigen Ausschusses an das Plenum vom 14.11.2001, BT-Drs. 14/7447 vom selben Tage, S. 4 und 5.

73 BT-Drs. 15/2004 vom 12.11.2003, S. 5.

74 Dieser Beschluss betrifft den Hilfseinsatz der Bundeswehr für humanitäre Maßnahmen der Vereinten Nationen in Somalia (Operation UNOSOM II), der zum Zeitpunkt des Urteils des Bundesverfassungsgerichts bereits (seit Ende März 1994) beendet war: Beschlussfassung des Deutschen Bundestages auf einen Antrag der Fraktionen der CDU/CSU und F.D.P., BTDrs. 12/4759 vom 21.04.1993, Zustimmung des Deutschen Bundestages am selben Tage. Der Beschluss lautet: »Der Deutsche Bundestag stimmt der Entscheidung der Bundesregierung vom 21. April 1993 zu, die Vereinten Nationen in befriedeten Regionen Somalias durch Soldaten der Bundeswehr bei humanitären Einsätzen zu unterstützen.«

75 DVParl-Protokoll vom 04.06.2003, dort Prof. Rupert Scholz, S. 7; Prof. Josef Isensee, S. 10; Jörg van Essen, S. 17; Winfried Nachtwei, S. 22; vgl. ferner Dieter Wiefelspütz (Parl.-vorbehalt - Fn. 1), S. 63. 
So wird das Parlament inzwischen in besonderen Sitzungen der Obleute des Verteidigungsausschusses durch die Bundesregierung über Einsätze der Spezialkräfte (KSK) unter Wahrung der Grundsätze zur Geheimhaltung unterrichtet - ein Verfahren, das grundsätzlich Anerkennung findet und auch die (nachträgliche) Information der Fraktionen in geeigneter Weise gestattet. ${ }^{76}$

\section{e. Welche Mehrheit ist erforderlich?}

Diskutiert wird zudem die Frage, ob die konstitutive Zustimmung des Deutschen Bundestages zu einem Einsatz bewaffneter Streitkräfte die Kanzlermehrheit (= absolute Mehrheit der Zahl der im Bundestag vertretenen Abgeordneten) erfordert oder ob die Mehrheit der abgegebenen Stimmen ausreicht. Zwischenzeitlich wurde sogar die Einführung einer Zwei-Drittel-Mehrheit für Einsatzbeschlüsse vorgeschlagen. ${ }^{77}$ Diese Frage ist allerdings bereits durch das Bundesverfassungsgericht entschieden: Der Bundestag habe über Einsätze bewaffneter Streitkräfte nach Maßgabe des Art. 42 Abs. 2 GG zu beschließen. ${ }^{78}$ Nach Art. 42 Abs. 2 Satz 1 GG ist zu einem Beschlusse des Bundestages »die Mehrheit der abgegebenen Stimmen erforderlich, soweit dieses Grundgesetz nichts anderes bestimmt.« Da weder die für Auslandseinsätze der Bundeswehr hauptsächlich als Rechtsgrundlage dienende Bestimmung des Art. 24 Abs. 2 GG noch das Urteil vom 12. Juli 1994 als Verfassungsrichterrecht abweichende Bestimmungen enthalten und auch sonst dem Grundgesetz zu dieser Frage nichts zu entnehmen ist, reicht die Mehrheit der abgegebenen Stimmen bei konstitutiven Beschlüssen über einen Streitkräfteeinsatz aus verfassungsrechtlicher Sicht nicht nur aus, sondern ist als geltendes Recht vorgegeben. Regelungen für eine qualifiziertere Mehrheit erforderten eine entsprechende Änderung des Grundgesetzes.

\section{f. Beteiligungsverfahren und Delegation auf einen Ausschuss}

Das Verfahren der Beteiligung des Deutschen Bundestages an Einsatzentscheidungen im Wege des konstitutiven Parlamentsbeschlusses lehnt sich bisher - mangels anderer Regelungen - an das Gesetzgebungsverfahren an. Dieses in der Staatspraxis mangels anderer Optionen und entsprechend den Vorgaben des Bundesverfassungsgerichts vom 12. Juli 1994 zu Art. 42 Abs. 2 GG $^{79}$ entwickelte Procedere betrifft weder ein Gesetz noch einen schlichten Parlamentsbeschluss, sondern einen konstitutiven Zustimmungsakt, den es so in der Geschäftsordnung des Deutschen Bundestages eigentlich gar nicht gibt. Der konstitutive Parlamentsbeschluss ist ein Akt mit Außenwirkung und Verbindlichkeit, also ein quasi exekutiver Akt. ${ }^{80}$ Das bisherige Verfahren könnte allerdings im Rahmen der vom Bundesverfassungsgericht formulierten und

76 DVParl-Protokoll vom 04.06.2003, dort Winfried Nachtwei, S. 22.

77 SPD und Grüne uneins über Hürden für Auslandseinsätze, Die Welt, 10.04.2002, S. 4; Werner Kohlhoff, Schröder hält an der Wehrpflicht fest - Kanzler will Entsendegesetz für Auslandseinsätze, Berliner Zeitung, 09.04.2002, S. 5.

78 BVerfGE 90, 286 [388].

79 Vgl. Fn. 78.

80 DVParl-Protokoll vom 04.06.2003, dort Prof. Josef Isensee, S. 3. 
verfassungsrechtlich verbindlichen Vorgaben gestrafft werden: So könnte die Überweisung an die Fachausschüsse ohne Lesung und Aussprache erfolgen, nach der Ausschussbefassung könnte eine Lesung im Plenum reichen und sodann die namentliche Abstimmung erfolgen, soweit die konkrete Zustimmung überhaupt vom gesamten Plenum erteilt werden muss. Auch hier gibt es verfassungsrechtliche Spielräume, in denen ein »Einsatzausschuss « als personell kleines und auch der Geheimhaltung besonders verpflichtetes Gremium bestimmte noch zu definierende Beschlüsse »im Auftrag « des Bundestages verbindlich fassen könnte. ${ }^{81}$

Im Zusammenhang mit der Frage der Delegation bestimmter Entscheidungen auf einen Einsatzausschuss wäre die Frage des Zeitpunkts der Parlamentsbeteiligung näher zu beleuchten. Die immer wieder ins Spiel gebrachte angebliche Langwierigkeit der konstitutiven Parlamentsentscheidungen besteht in Wirklichkeit nicht: So wurde die Zustimmung zur deutschen Beteiligung an UNTAES, ${ }^{82}$ zu SFOR I ${ }^{83}$ zu SFOR II ${ }^{84}$ oder zur NATO-Operation ALLIED HARMONY in Mazedonien ${ }^{85}$ binnen zwei Tagen nach der Kabinettentscheidung, zur Extraction Force für den Kosovo ${ }^{86}$ zur INTERFET-Operation in Ost-Timor, ${ }^{87}$ zur ISAF-Operation in Afghanistan ${ }^{88}$ oder zur EUOperation Concordia ${ }^{89}$ am Tage nach der Kabinettentscheidung und schließlich die Zustimmung zur deutschen Beteiligung an $\mathrm{KFOR}^{90}$ oder an der NATO-Operation AMBER FOX ${ }^{91}$ am selben Tage wie die Kabinettentscheidung erteilt. Da solche Entscheidungen das Ergebnis eines meist Wochen oder sogar Monate dauernden Prozesses sind, der öffentlich begleitet und in den Gremien von UNO, NATO oder EU vorbereitet wird, wird es in der Mehrzahl der Fälle möglich sein, unter Einhaltung parlamentarischer Gepflogenheiten eine Einsatzentscheidung binnen weniger Tage herbeizuführen. Dies gilt auch für die zunehmend diskutierte 5-Tage-Frist, in denen der deutsche Anteil der NATO Response Force bei einem konkreten Einsatz zur Verfügung stehen müsste. Wenn der scheidende NATO-Generalsekretär Lord Robertson auch mit Blick auf die Bundesrepublik schnellere nationale Entscheidungsprozesse fordert, um den Herausforderungen der Zukunft gerecht zu werden, geht diese Forderung an der deutschen Verfassungswirklichkeit vorbei. Dies ändert allerdings nichts daran, dass im Rahmen der Vorgaben des Bundesverfassungsgerichts die Prozeduren

81 DVParl-Protokoll vom 04.06.2003, dort Dieter Wiefelspütz, S. 36: »Ein solcher Ausschuss kann selbstverständlich stellvertretend für das Parlament verbindlich entscheiden. «

82 BT-Drs. 13/3708 vom 07.02.1996 = Kabinettsbeschluss, Zustimmung des Deutschen Bundestages am 09.02.1996.

83 BT-Drs. 13/6500 vom 11.12.1996, Zustimmung des Deutschen Bundestages am 13.12.1996.

84 BT-Drs. 13/10977 vom 17.06.1998, Zustimmung des Deutschen Bundestages am 19.06.1998.

85 BT-Drs. 15/127 vom 03.12.2002, Zustimmung des Deutschen Bundestages am 05.12.2002.

86 BT-Drs. 14/47 vom 18.11.1998, Zustimmung des Deutschen Bundestages am 19.11.1998.

87 BT-Drs. 14/1719 vom 06.10.1999, Zustimmung des Deutschen Bundestages am 07.10.1999.

88 BT-Drs. 14/7930 vom 21.12.2001, Zustimmung des Deutschen Bundestages am 22.12.2002.

89 BT-Drs. 15/696 vom 19.03.2003, Zustimmung des Deutschen Bundestages am 20.03.2003.

90 BT-Drs. 14/1133 vom 11.06.1999, Zustimmung des Deutschen Bundestages am selben Tage.

91 BT-Drs. 14/6970 vom 27.09.2001, Zustimmung des Deutschen Bundestages am selben Tage. 
generell vereinfacht und für bestimmte Einsatzarten auf einen Einsatzausschuss delegiert werden könnten, der dann noch schneller entscheiden könnte.

Wiefelspütz sind aufgrund seiner jüngsten Arbeit vertiefte Hinweise zur Möglichkeit und Rechtmäßigkeit der Delegation von Plenumsrechten an einen Ausschuss zu verdanken: Danach verfügt die Staatspraxis bereits über eine Reihe von bewährten Möglichkeiten, in denen Plenarzuständigkeiten auf einen Ausschuss delegiert wurden, und zwar zur abschließenden und verbindlichen Entscheidung. ${ }^{92}$ Als Beispiele nennt er die Wahl von Verfassungsrichtern gemäß Art. 94 Abs. 1 Satz 2 GG i. V. m. § 6 Abs. 2 BVerfGG im dafür eingerichteten Richterwahlausschuss, die Entscheidungskompetenz des Haushaltsausschusses bei der Entsperrung von im Haushaltsgesetz eingesetzten Haushaltsmitteln, die Übertragung eines Teils der Immunitätsentscheidung des Bundestages auf den Geschäftsordnungsausschuss (Vorbescheid) sowie die Wahrnehmung der Rechte des Bundestages gegenüber der Bundesregierung durch den Ausschuss für Angelegenheiten der Europäischen Union. Besondere Hervorhebung verdiene das parlamentarische Untersuchungsrecht, das dem Plenum des Bundestages zustehe, aber vom (jeweils eingesetzten oder wie im Falle des Art. 45a Abs. 2 Satz 1 GG - Verteidigungsausschuss hat die Rechte qua Grundgesetz - jederzeit konstituierbaren) Untersuchungsausschuss ausgeübt werde. ${ }^{93}$

Vor dem Hintergrund einer inzwischen jahrzehntelangen, auch vom Bundesverfassungsgericht nicht beanstandeten Staatspraxis ${ }^{94}$ sei das entscheidende Kriterium für die Abgrenzung von zulässiger und unzulässiger parlamentarischer Aufgabenübertragung die sachliche Notwendigkeit bzw. die Funktionsgerechtigkeit. ${ }^{95}$ Es komme darauf an, dass sich die Übertragung als sachgerechte, den Interessen von Regierung und Parlament gleichermaßen entsprechende Lösung erweise. Je nach politischem Gewicht könne das Plenum den Ausschüssen das Recht einräumen, lediglich vorbereitende Beschlüsse, aber auch Entscheidungen zu treffen, die unter einem Vorbehalt stehen oder gar den Charakter einer endgültigen Entscheidung mit Außenwirkung haben. ${ }^{96}$ Die Organisationsgewalt des Bundestages für den parlamentarischen Bereich umfasse auch die Befugnis, Entscheidungsbefugnisse auf Teile des Bundestages zu übertragen, sei es bei der Rechtssetzung, bei Wahlen oder bei der Wahrnehmung des konstitutiven Parlamentsvorbehalts. Dies gelte allerdings nicht in den Fällen, in denen das Grundgesetz erkennbar den Parlamentsvorbehalt als Plenarvorbehalt verstanden wissen wolle. ${ }^{97}$ Wesentliche Entscheidungen, die sich durch ihr Gewicht, ihre Bedeutung und Reichweite auszeichneten, insbesondere die erstmalige Beteiligung an einem Einsatz, seien demnach dem Plenum vorbehalten, nachrangige Entscheidungen dürften delegiert werden. ${ }^{98}$ Dies kann jedoch nach den hier entwickelten Kriterien

92 Dieter Wiefelspütz (Parl.-vorbehalt - Fn. 1), S. 70 ff.

93 Dieter Wiefelspütz (Parl.-vorbehalt - Fn. 1), S. 70 ff. (Hervorhebungen und Klammerzusätze durch den Autor dieses Beitrages).

94 BVerfGE 40, 356 [362 ff.]; 70, 324 [364].

95 Dieter Wiefelspütz (Parl.-vorbehalt - Fn. 1), S. 74 und 75.

96 Dieter Wiefelspütz (Parl.-vorbehalt - Fn. 1), S. 75.

97 Dieter Wiefelspütz (Parl.-vorbehalt - Fn. 1), S. 79.

98 Dieter Wiefelspütz (Parl.-vorbehalt - Fn. 1), S. 80. 
nicht gelten, wenn das oberste Gebot die Funktionalität der Delegation ist: So müssten auch Erstentscheidungen $\mathrm{zu}$ einem Einsatz eines kleinen Kontingents ${ }^{99}$ oder aus Praktikabilitätserwägungen geheimhaltungs- oder sonst eilbedürftige Entscheidungen dem Einsatzausschuss übertragen werden können.

\section{g. Bewaffnete Selbstschutzkomponente}

Soweit anhand des Beispiels eines Einsatzes deutscher ISAF-Soldaten zur Hilfe nach einem Erdbeben in Mazar-il-Sharif in Nord-Afghanistan über die Frage diskutiert wird, ob dies einen neuen, vom Bundestagsmandat für ISAF zu Beginn des Jahres 2002 nicht abgedeckten Einsatz bewaffneter Streitkräfte darstellte, weil der ISAF-Einsatz auf Kabul und Umgebung beschränkt, die Hilfstruppen aber von einer bewaffneten Sicherungskomponente begleitet und außerhalb des festgelegten Einsatzgebiets eingesetzt waren, stellt dies einen Grenzfall dar. Fraglich ist, ob es zur Beurteilung auf den humanitären Schwerpunkt des Einsatzes (Erdbebenhilfe) oder darauf ankommt, ob dies eine neue Einsatzqualität ist. ${ }^{100}$ Stellt man auf ersteres ab, war der Einsatz zulässig. Stellt man auf die Bewaffnung ab, kann man angesichts des konkreten Einsatzbeschlusses des Deutschen Bundestages, der den ISAF-Einsatz auf Kabul und Umgebung und den Einsatzzweck auf »Sicherheitsunterstützung « für die neue afghanische Interimsregierung und VN-Personal festlegte, zu dem Schluss gelangen, dies sei eine bisher nicht gebilligter neuer Einsatz. $\mathrm{Zu}$ diesem Schluss gelangt man auch, wenn man auf den Grad der Wahrscheinlichkeit der Einbeziehung dieses Hilfskontingents in bewaffnete Unternehmungen abstellte: Die Beteiligung einer bewaffneten Sicherungskomponente war angesichts der schwierigen Sicherheitslage außerhalb Kabuls offenbar erforderlich, weil Überfälle auf die medizinischen Hilfskräfte befürchtet werden mussten. Trotzdem fragt sich, ob sich bei einer solchen Hilfsaktion ein militärtypisches (kriegerisches) Risiko konkretisiert oder ob die Vorsorge für eine effektive Selbstverteidigung bereits als Einsatz bewaffneter Streitkräfte im Rechtssinne anzusehen ist, obwohl weder ein Konflikt mit der eingesetzten Regierung droht, weil diese die ISAF-Truppe ausdrücklich um Hilfe ersucht hatte, noch die Wahrscheinlichkeit einer Einbeziehung in bewaffnete Unternehmungen konkret abgeschätzt werden kann. Stattdessen entspricht der Einsatz einer bewaffneten Selbstschutzkomponente in solchen Fällen dem Prinzip der Fürsorge sowie kluger militärischer Vorsorge. Bei solchen Konstellationen fragt sich, ob Definitionsversuche nicht an natürliche Grenzen stoßen oder durch neue Regelungen aufgelöst werden könnten, die das Mitführen von Waffen zum Eigen- und Materialschutz nicht als »Einsatz bewaffneter Streitkräfte« im technischen Sinne einstuften.

99 Beispiele aus der jüngeren Staatspraxis: Deutsche Beteiligung an INTERFET in Ost-Timor, BT-Drs. 14/1719 vom 06.10.1999, Zustimmung des Deutschen Bundestages am 07.10.1999, Ziffer 5: Bereitstellung von bis zu 100 Soldaten; Deutsche Beteiligung an der EU-Operation Concordia in Mazedonien, BT-Drs. 15/696 vom 19.03.2003, Zustimmung des Deutschen Bundestages am 20.03.2003, Ziffer 8: Bereitstellung von bis zu 70 Soldaten.

100 DVParl-Protokoll vom 04.06.2003, dort Jörg van Essen, S. 18. 


\section{Offene Fragen für die Regierungspraxis}

Im Rahmen der Regierungspraxis stellen sich in zahlreichen Fällen wie bei der Definition des Begriffs »Einsatz bewaffneter Streitkräfte «, beim Rückholrecht, bei der Frage des Präzisierungsgrades der zur Zustimmung vorgelegten Beschlüsse, beim bisher nicht geregelten Beteiligungsverfahren oder bei der Einschätzung eines besonderen Auftrages für ein Hilfskontingent mit Selbstschutzkomponente grundsätzlich dieselben Fragen wie im parlamentarischen Raum. Dabei ist nach den bisherigen Erfahrungen jeder Einsatz neu zu bewerten und vollzieht sich unter anderen Rahmenbedingungen als jeder vorhergehende Einsatz. Allerdings muss die Bundesregierung angesichts der verbindlichen Vorgaben des Bundesverfassungsgerichts zum Begriff des »Einsatzes bewaffneter Streitkräfte« aus den bereits oben dargelegten Gründen bisher davon ausgehen, dass auch der Einsatz eines einzelnen Soldaten als Einsatz unter Parlamentsvorbehalt zu qualifizieren ist. ${ }^{101}$ Damit ist auch klar, dass sämtliche Varianten von Vorauspersonal für einen Einsatz, der sich insgesamt als Einsatz bewaffneter Streitkräfte darstellt, nach geltender Rechtslage erst entsandt werden dürfen, wenn der Deutsche Bundestag seine konstitutive Zustimmung erteilt hat; einzige zulässige Ausnahme ist insoweit der Fall einer Gefahr im Verzuge. Durch dieses Verständnis der Vorgaben des Bundesverfassungsgerichts hat sich eine Staatspraxis entwickelt, bei der die Bundesregierung im Zweifel eher den Parlamentsbeschluss abwartet, was sich sogar auf bestimmte Vorbereitungshandlungen wie den Abschluss von Transportverträgen erstreckt. ${ }^{102}$ Es wäre hilfreich, dieses Verständnis durch abweichende neue Regeln in einem Parlamentsbeteiligungsgesetz neu zu regeln.

Außerdem geht das Urteil erkennbar davon aus, dass auf Seiten der Exekutive nur die Bundesregierung als Kollegialorgan und auf Seiten des Parlaments nur das Plenum des Deutschen Bundestages wirklich ermächtigt sind, an einem Beschluss über die Beteiligung deutscher Soldaten an einem Einsatz bewaffneter Streitkräfte als Entscheidungsträger mitzuwirken. Zusätzlich sollen, wenn irgend möglich, die Fachausschüsse des Deutschen Bundestages vor einer Entscheidung im Plenum mit dem geplanten Einsatz befasst werden. ${ }^{103}$ Nicht Gegenstand der konstitutiven Zustimmung des Bundestages zu einem Einsatz bewaffneter deutscher Streitkräfte ist die Beteiligung von Beamten der Polizei, des BGS oder anderer Bundes- oder Länderbehörden oder die Beteiligung von Zivilpersonen an einem solchen Einsatz.

Besondere Probleme für die Regierungspraxis werfen die Einsätze einzelner Soldaten in Austauschprogrammen, als Experten bei Operationen, an denen sich die Bundesrepublik ansonsten nicht beteiligt, und insbesondere der vorübergehende Einsatz kleinerer Gruppen von Soldaten als Fact Finding Team und sonstiges Vorauspersonal auf, die einen Einsatz erst vorbereiten sollen und oft nicht entsandt werden dürfen, weil ihr Einsatz bisher als »Einsatz bewaffneter Streitkräfte « anzusehen ist und zum Zeitpunkt der geplanten Entsendung ein zustimmender Bundestagsbeschluss noch gar

101 Vgl. Fn. 45 und 50.

102 DVParl-Protokoll vom 04.06.2003, dort Dieter Weingärtner (Leiter Abteilung Recht im BMVg), S. 44/45.

103 BVerfGE 90, 286 [387 - 390]. 
nicht vorliegt oder vorliegen kann; denn dieses Personal gewinnt häufig erst die Erkenntnisse, die nach ihrer Rückkehr eine militärische Einsatzplanung ermöglichen und sodann in einen Kabinetts- und Bundestagsbeschluss münden. Sie müssen aber in der Regel Handfeuerwaffen zum Eigenschutz mitführen, weil sie den Auftrag zur Vorbereitung eines weiteren Einsatzes in einem unstabilen Umfeld ausführen; sie haben aber weder die Mittel noch den Auftrag, sich in bewaffnete Unternehmungen von solchem Gewicht verstricken zu lassen oder sie zu beginnen, dass die oben beschriebene Erheblichkeitsschwelle erreicht wird. In einem Parlamentsbeteiligungsgesetz könnten solche Kleinsteinsätze und solche von geringer Bedeutung entweder als von vorneherein gebilligt oder als »untechnisch«, also nicht zustimmungsbedürftig geregelt werden. Überstiege die Zahl der eingesetzten Soldaten in solchen Missionen eine bestimmte Zahl oder dauerte ihr Einsatz länger als eine festzulegende Frist, könnte die Zustimmungsbefugnis auf einen Ausschuss delegiert werden.

Dieser Ausschuss sollte als Einsatzausschuss bezeichnet werden; Vorschläge für seine Zusammensetzung wurden bereits öffentlich gemacht. ${ }^{104}$ Fraglich könnte ferner sein, ob - allerdings nicht im Parlamentsbeteiligungsgesetz, sondern in der Geschäftsordnung des Bundesregierung - ein Einsatzrat als Kabinettsausschuss gebildet werden sollte, der grundsätzlich vom Bundeskanzler geleitet würde und dem immer BMJ, BMVg und Außenminister, bei fallweiser Zuziehung auf Entscheidung des Bundeskanzlers auch andere Minister angehören, falls eil- oder geheimhaltungsbedürftige Entscheidungen zu treffen sind. Dieser Einsatzrat wäre direkter Ansprechpartner für den Einsatzausschuss des Deutschen Bundestages.

Denn in dem bisher einzigen Anwendungsfall einer »Gefahr-im-Verzug « - Entscheidung, der Operation LIBELLE in Albanien, ${ }^{105}$ gab es keine Regelung, ob das gesamte Kabinett (entsprechend dem Urteil vom 12. Juli 1994), der Bundesminister der Verteidigung nach Art. 65a GG oder nur der Bundeskanzler allein oder ob der Bundeskanzler mit dem Außen- und dem Verteidigungsminister gemeinsam die Entscheidung zum Einsatz zu treffen hatten. Dies wäre nach der Schaffung eines Kabinettsausschusses für solche Fragen eindeutig geregelt. Dieser Einsatzrat könnte auch mit Entscheidungen befasst werden, in denen aus sonstigen Gründen Eilbedürftigkeit gegeben wäre.

Klare Regelungen über Zuständigkeiten und Inhalte könnten für die Zukunft außerdem die Zahl der Protokollerklärungen verringern helfen, das Verfahren vereinfachen und Rechtssicherheit steigern. Da der Inhalt der Beschlüsse und Anträge, die dem deutschen Bundestag vorgelegt werden, insbesondere bei neuen Einsätzen als bewährt angesehen wird, könnte auch ein Grundkanon von notwendigen Inhalten eines Zustimmungsantrages festgeschrieben werden. Mit Hilfe eines neuen Gremiums im Bundestag und evtl. auch in der Bundesregierung könnten bisherige Verfahren, die »informell « funktionieren, deren Stellenwert aber verfassungsrechtlich unklar ist, wie z. B. die Information von Obleuten, Fraktionsvorsitzenden etc., künftig obsolet werden.

104 Undatierter Gesetzentwurf (Arbeitspapier) der Abgeordneten und der Fraktion der CDU/ CSU (Fn. 8), § 6. Gesetzentwurf der Abgeordneten und der Fraktion der FDP (Fn. 8), §§ 5 ff.

105 Vgl. Fn. 27. 


\section{Die Vorstellungen der Parteien}

\section{a. Gemeinsamkeiten}

Im parlamentarischen Raum besteht bei allen Unterschieden in den bisherigen Ansätzen zur Formulierung eines Parlamentsbeteiligungsgesetzes jedenfalls zwischen SPD, Bündnis 90 / Die Grünen, CDU/CSU und FDP Einigkeit, dass der Einsatz bewaffneter deutscher Streitkräfte außerhalb des Geltungsbereichs des Grundgesetzes der grundsätzlich vorherigen konstitutiven Zustimmung des Deutsche Bundestages bedarf. ${ }^{106}$ Es besteht ferner Übereinstimmung zwischen SPD, FDP und Bündnis 90 / Die Grünen, dass es den Entwurf eines Parlamentsbeteiligungsgesetz zur näheren Regelung des Zustimmungsverfahrens des Deutschen Bundestages auf Anträge der Bundesregierung zu einem Einsatz bewaffneter Streitkräfte möglichst aus der Mitte des Parlaments geben sollte, dass ein Antrag der Bundesregierung zur Einholung dieser Zustimmung notwendig ist und dass man sich im wesentlichen an die Vorgaben des Bundesverfassungsgerichts halten will. Scholz und van Essen betonen, dass insbesondere das Grundsatzjudikat vom 12. Juli 1994 verbindliches Verfassungsrecht darstellt. ${ }^{107}$ Vertreter der CDU/CSU wollen allerdings die Bundesregierung in die Pflicht nehmen, einen solchen Gesetzentwurf vorzulegen. ${ }^{108}$ Auch die Vorstellungen hinsichtlich des erforderlichen Grades an Bestimmtheit der neuen Regelungen ähneln sich: Während Scholz ein erhebliches Maß an Offenheit fordert, ${ }^{109}$ treten Wiefelspütz und Pofalla mit ihrer Forderung nach einem möglichst großen Abstraktionsgrad für dasselbe Ziel

106 Da das Gesetz Form und Ausmaß der Beteiligung des Deutschen Bundestages beim Einsatz bewaffneter Streitkräfte im Ausland regeln soll (§ 1 Abs. 1 Satz 1 des Gemeinsamen »Entwurf(es) von SPD und Bündnis 90/Grüne für ein Parlamentsbeteiligungsgesetz vom 27.11.2003 ), erscheint der Hinweis in $\S 1$ Abs. 1 Satz 2 dieses Entwurfs, Art. 115a GG bleibe davon unberührt, als nicht notwendige ergänzende Regelung. Denn ein einfaches Gesetz darf ohnehin keine verfassungsändernden Regelungen enthalten. Zudem regelt Art. 115a GG das Zustandekommen der Feststellung des Verteidigungsfalles mit den in Art. $115 \mathrm{~b}$ GG ff. vorgesehenen innerstaatlichen Folgen, die beim Auslandseinsatz zumindest bisher keine Rolle gespielt haben.

107 DVParl-Protokoll vom 04.06.2003, dort Prof. Rupert Scholz, S. 3 und Jörg van Essen, S. 16.

108 DVParl-Protokoll vom 04.06.2003, dort Prof. Rupert Scholz, S. 4: Scholz spricht immerhin von Gestaltungsmöglichkeiten des Parlaments; MdB Hans-Peter Bartels (SPD) spricht von gemeinsamen Anstrengungen des gesamten Parlaments und der Erarbeitung eines gemeinsamen Entwurfs, S. 14; Winfried Nachtwei (Bündnis 90 / Die Grünen) spricht sich jedenfalls für eine Regelung aus, S. 20/21; Jörg van Essen (FDP) spricht sich für eine gemeinsame Lösung aus, S. 31; Dieter Wiefelspütz spricht von einem genuinen Parlamentsrecht - er wünsche sich ein Parlament, das sich selber auf den Hintern setzte und die Verantwortung für die Entscheidung übernehme, anstatt sie abzugeben, S. 35; Demgegenüber sieht Ronald Pofalla (CDU/CSU) die Bundesregierung bei der Erarbeitung eines Entwurfs in der Pflicht, S. 25. Die FDP hat inzwischen insgesamt 3 Entwürfe selbst vorgelegt; SPD und Bündnis 90 / Die Grünen haben zunächst je einen eigenen Entwurf bzw. Hinweise, inzwischen auch einen gemeinsamen Entwurf vorgelegt (vgl. Fn. 8). Damit wird der Wille des Parlaments deutlich, die parlamentarischen Beteiligungsrechte in einem eigenen Gesetzentwurf zu regeln.

109 DVParl-Protokoll vom 04.06.2003, dort Prof. Rupert Scholz, S. 7 und S. 9. 
ein. ${ }^{110}$ Die bisher vorgelegten Gesetzentwürfe zeigen alle eine sehr große, z. T. vielleicht zu große Abstraktion; ein höherer Detaillierungsgrad erscheint in einer Reihe von Fragen notwendig, um das Ziel von Rechtsklarheit und wirklicher Verfahrensvereinfachung zu erreichen.

Einigkeit besteht ferner, dass rein humanitäre Hilfseinsätze ohne Waffen nicht als Einsatz bewaffneter Streitkräfte im Rechtssinne angesehen werden. ${ }^{111}$ Zumindest weitgehende Einigkeit könnte man in der Frage der Behandlung im Falle von Gefahr im Verzug sehen: So möchten SPD, CDU/CSU und Bündnis 90 / Die Grünen an den Vorgaben des Bundesverfassungsgerichts zu dieser Frage gar nichts ändern, während die FDP diese Frage dem Einsatzausschuss (dort als Ausschuss für besondere Auslandseinsätze bezeichnet) ${ }^{112}$ überlassen will. Hier scheint eine Einigung möglich.

Ferner wird die besondere Festschreibung von Informationspflichten der Bundesregierung für den Deutschen Bundestag, wenn auch mit unterschiedlichen Ausprägungsgraden gefordert; auch hier sollte eine Einigung möglich sein, zumal bereits derzeit laufend das Parlament von der Bundesregierung zu den Auslandseinsätzen unterrichtet wird. ${ }^{113}$

Außerdem sehen die Entwürfe von FDP sowie CDU/CSU besondere Regeln für die Geheimhaltung vor; ${ }^{114}$ Bündnis 90 / Die Grünen sehen das Modell des Verteidigungsausschusses und die dort inzwischen etablierten Verfahren der Information über den grundsätzlich geheimhaltungsbedürftigen Einsatz von Spezialkräften als gut funktionierend an. ${ }^{115}$

\section{b. Divergierende Vorstellungen}

Auch wenn der von der SPD vorgelegte erste Gesetzentwurf keinen Hinweis zu einen Entsende- oder Einsatzausschuss enthält, gibt es doch Hinweise auf die Befürwortung eines solchen Ausschusses auch aus der größeren Regierungspartei. ${ }^{116}$ Während FDP

110 DVParl-Protokoll vom 04.06.2003, dort Ronald Pofalla (CDU/CSU), S. 26 und Dieter Wiefelspütz (SPD), S. 36.

111 Vgl. die Vorschläge gemäß Fn. 8.

112 Gesetzentwurf der Abgeordneten und der Fraktion der FDP (Fn. 8), dort $\S 5$ ff.

113 DVParl-Protokoll vom 04.06.2003, dort Hans-Peter Bartels (SPD), S. 14: »Ein Informationsrecht ist ohnehin erforderlich. ... Ein sinnvolles Verfahren könnte sein, halbjährig oder vierteljährig das ganze Parlament und regelmäßig sitzungswöchentlich die zuständigen Ausschüsse $\mathrm{zu}$ informieren. Im Übrigen ist es in der Praxis heute so. Da würde man nichts ändern; man würde nur formalisieren.« Positionspapier der Bundestagsfraktion Bündnis 90 / Die Grünen (Fn. 8), Ziffer 2.6. Undatierter Gesetzentwurf (Arbeitspapier) der Abgeordneten und der Fraktion der CDU/CSU (Fn. 8), § 6. Teilweise wird zwischen Informationen für den Ausschuss und für das Plenum unterschieden: Gesetzentwurf der Abgeordneten und der Fraktion der FDP (Fn. 8), § 8. Entwurf der SPD-Bundestagsfraktion (Fn. 8), § 6. Gemeinsamer »Entwurf von SPD und Bündnis 90/Grüne für ein Parlamentsbeteiligungsgesetz vom 27.11.2003«, § 6 .

114 Undatierter Gesetzentwurf (Arbeitspapier) der Abgeordneten und der Fraktion der CDU/ CSU (Fn. 8), § 6. Gesetzentwurf der Abgeordneten und der Fraktion der FDP (Fn. 8), § 9.

115 DVParl-Protokoll vom 04.06.2003, dort Winfried Nachtwei, S. 22.

116 DVParl-Protokoll vom 04.06.2003, dort Dieter Wiefelspütz, S. 36: »Was soll und kann der Entsendeausschuss regeln? Lieber Professor Scholz, wir haben den Art. 45 GG. Mindestens wäre ein Art. 45 Abs. 2 möglich, in dem stünde: Der Deutsche Bundestag bestellt einen Ent- 
und CDU einen solchen Ausschuss ebenfalls befürworten, ${ }^{117}$ lehnen Bündnis 90 / Die Grünen einen neuen Ausschuss ab und wollen den Auswärtigen Ausschuss federführend und zumindest den Verteidigungs- und den Rechtsausschuss mitberatend mit bestimmten, aber noch nicht näher definierten Angelegenheiten befassen. ${ }^{118}$ Der neueste gemeinsame Gesetzentwurf der Regierungsparteien enthält ebenfalls keine Regelung zu einem Einsatz- oder Entsendeausschuss. ${ }^{119}$

Die SPD vertrat bisher als einzige Partei dezidiert die Ansicht, dass auch ein Einsatz bewaffneter Streitkräfte vorliege, wenn die Einbeziehung in bewaffnete Unternehmungen zu erwarten sei; ${ }^{120}$ diesen Gedanken hat der gemeinsame Entwurf der Regierungsparteien nunmehr übernommen. ${ }^{121}$ Dies entspricht allerdings den Hinweisen des Bundesverfassungsgerichts in der jüngsten AWACS-Eilentscheidung ${ }^{122}$ und sollte von den anderen Parteien ebenfalls bedacht werden. Ferner vertritt die SPD eine moderne Auffassung, was Hilfseinsätze der Bundeswehr angeht: Dabei will sie auf den konstitutiven Parlamentsvorbehalt auch dann verzichten, wenn die Soldaten lediglich Waffen zur Selbstverteidigung mitführen. ${ }^{123}$ Dies wurde im gemeinsamen Gesetzentwurf der Regierungsparteien inzwischen ebenfalls übernommen. ${ }^{124}$

Völlig unklar ist bisher, was ein Einsatz von geringer Bedeutung sein soll und wie solche Fälle zu behandeln wären. Nach Auffassung der SPD sollte ein Einsatz von geringer Bedeutung vorliegen, wenn einzelne Soldaten in Austauschprogrammen bei verbündeten Streitkräfte Dienst verrichten oder wenn einzelne Soldaten im Rahmen der VN, der NATO, der OSZE oder der EU oder bei einem Erkundungskommando, das Handfeuerwaffen nur zur Selbstverteidigung mitführt, eingesetzt werden. ${ }^{125}$ Dieser Vorschlag wurde inzwischen im gemeinsamen Entwurf der Regierungsparteien übernommen; zusätzlich wird ausgeführt, ein Einsatz sei dann von geringer Bedeutung, wenn die Zahl der eingesetzten Soldaten gering sei und der Einsatz auf Grund der übrigen Begleitumstände keine herausgehobene Bedeutung habe. ${ }^{126}$ Die FDP hat bisher nur auf den Fall eines Einsatzes einzelner Soldaten bei den VN, der NATO, der

sendeausschuss und legt dessen Befugnisse gesetzlich fest. Ein solcher Ausschuss kann selbstverständlich stellvertretend für das Parlament verbindlich entscheiden. Meine persönliche Auffassung ist, dass man dies auch durch ein Gesetz erreichen könnte und nicht unbedingt eine Verfassungsänderung braucht. Darüber kann man aber streiten.«

117 Undatierter Gesetzentwurf (Arbeitspapier) der Abgeordneten und der Fraktion der CDU/CSU (Fn. 8), § 6. Gesetzentwurf der Abgeordneten und der Fraktion der FDP (Fn. 8), §§ 5 ff.

118 Positionspapier der Bundestagsfraktion Bündnis 90 / Die Grünen (Fn. 8), Ziffer 2.5.

119 Vgl. Fn. 8.

120 Entwurf der SPD-Bundestagsfraktion (Fn. 8), § 2 Abs. 1.

121 Gemeinsamer »Entwurf von SPD und Bündnis 90/Grüne für ein Parlamentsbeteiligungsgesetz vom 27.11.2003 (Fn. 8), § 2 Abs. 1.

$122 \mathrm{Vgl}$. BVerfG a. a. O. (Fn. 48), Rn. $33-35$.

123 Entwurf der SPD-Bundestagsfraktion (Fn. 8), § 2 Abs. 2.

124 Gemeinsamer »Entwurf von SPD und Bündnis 90/Grüne für ein Parlamentsbeteiligungsgesetz vom 27.11.2003 «(Fn. 8), ebenfalls § 2 Abs. 2.

125 Entwurf der SPD-Bundestagsfraktion (Fn. 8), § 4 Abs. 2.

126 Gemeinsamer »Entwurf von SPD und Bündnis 90/Grüne für ein Parlamentsbeteiligungsgesetz vom 27.11.2003«(Fn. 8), § 4 Abs. 2 und 3. 
OSZE oder der EU aufgeführt; ${ }^{127}$ die CDU/CSU will einen Einsatz von geringer Bedeutung anerkennen, wenn eine bestimmte, noch nicht festgelegte Personalstärke nicht überschritten wird. Möglicherweise werden auch die Fälle des Einsatzes im Rahmen völkerrechtlicher Verpflichtungen oder eine reine Verlängerung eines Einsatzes bis zu einem Jahr so verstanden. ${ }^{128}$

Zum Verfahren bei solchen Einsätzen von geringer Bedeutung hatte die SPD bereits einen dezidierten Vorschlag unterbreitet, der inzwischen im gemeinsamen Entwurf der Regierungsparteien weiter detailliert wurde. ${ }^{129}$ Nach dem gemeinsamen Entwurf kann die Zustimmung des Parlaments bei Einsätzen von geringer Bedeutung im vereinfachten Verfahren erteilt werden. Die Bundesregierung habe begründet darzulegen, aus welchen Gründen der bevorstehende Einsatz von geringer Bedeutung sei. Der Präsident des Deutschen Bundestages übermittle den Antrag an die Vorsitzenden der Fraktionen sowie die Vorsitzenden des Auswärtigen Ausschusses und des Verteidigungsausschusses und je einen von jeder in diesen Ausschüssen vertretenen Fraktionen benannten Vertreter (Obleute) und lasse den Antrag als Bundestagsdrucksache an alle Mitglieder des Bundestages verteilen. ${ }^{130}$ Die Zustimmung gelte als erteilt, wenn nicht innerhalb von sieben Tagen nach der Verteilung von einer Fraktion oder fünf vom Hundert der Mitglieder des Bundestages eine Befassung des Bundestages verlangt werde. Werde die Befassung des Bundestages verlangt, entscheide dieser. ${ }^{131}$ Eine Vereinfachung erreicht dieser Vorschlag für die Bundesregierung gar nicht (Begründungszwang, ohne die Anforderungen an die Begründung dezidiert festzuschreiben) und für das Parlament nur dann, wenn eine Befassung des Bundestages nicht zustande kommt.

Nach Auffassung von Bündnis 90 / Die Grünen sollten reine Verlängerungsbeschlüsse im Plenum ohne Aussprache erfolgen; dies könne auch in der Geschäftsordnung geregelt werden. ${ }^{132}$ Die SPD bezog reine Verlängerungsbeschlüsse in die Fälle »von geringer Bedeutung « ein; ${ }^{133}$ dies wurde im gemeinsamen Entwurf der Regierungsparteien inzwischen übernommen. ${ }^{134}$ Danach findet das Verfahren nach $\S 4$ (vereinfachtes Zustimmungsverfahren) auf Verlängerungsbeschlüsse ohne inhaltliche Änderung Anwendung. Die FDP hat die Frage nur in der Erläuterung zu $§ 6$ ihres

127 Gesetzentwurf der Abgeordneten und der Fraktion der FDP (Fn. 8), § 6 Abs. 1 c.

128 Undatierter Gesetzentwurf (Arbeitspapier) der Abgeordneten und der Fraktion der CDU/ CSU (Fn. 8), § 3.

129 Entwurf der SPD-Bundestagsfraktion (Fn. 8), § 4.

130 Vgl. Positionspapier der Bundestagsfraktion Bündnis 90 / Die Grünen (Fn. 8), Ziffer 2.1 (Entscheidung des Parlaments wie beim Gesetzgebungsverfahren), Ziffer 2. 2 (Vollständiges Rückholrecht) sowie Ziffer 2.5 (mindestens drei Ausschüsse und Entscheidung des Plenums bei entsprechendem Votum einer Fraktion oder von $5 \%$ der Mitglieder des Deutschen Bundestages).

131 Gemeinsamer »Entwurf von SPD und Bündnis 90/Grüne für ein Parlamentsbeteiligungsgesetz vom 27.11.2003«(Fn. 8), § 4 Abs. 1.

132 Positionspapier der Bundestagsfraktion Bündnis 90 / Die Grünen (Fn. 8), Ziffer 2.4.

133 Entwurf der SPD-Bundestagsfraktion (Fn. 8), § 4 Abs. 3.

134 Gemeinsamer »Entwurf von SPD und Bündnis 90/Grüne für ein Parlamentsbeteiligungsgesetz vom 27.11.2003« (Fn. 8), § 7. 
jüngsten Entwurfs angesprochen: Demnach kann die unstreitige Verlängerung eines bereits genehmigten Einsatzes vom Bundestag auf den Ausschuss für besondere Auslandseinsätze delegiert werden. ${ }^{135}$

Bei der immer wieder aufgeworfenen Frage eines Rückholrechts gehen die Meinungen besonders weit auseinander: Am weitesten geht ein Vorschlag von BM a. D. Wolfgang Schäuble, demzufolge sich das Bundesverfassungsgericht in dieser Frage geirrt haben soll. Er regt an, das in den USA gültige System zu übernehmen, bei dem zunächst die Exekutive in Gestalt des Präsidenten über den Einsatz entscheidet und ihn vollzieht. Nach bestimmten Mindestfristen, z. B. nach 30 oder 60 Tagen, habe das Parlament die Möglichkeit, den Einsatz zu beenden und die Streitkräfte zurückzuholen. ${ }^{136}$

Der ehemalige Verteidigungsminister Volker Rühe ist gegen den Schäuble-Vorstoß: Es müsse schwer sein, Soldaten im Ausland einzusetzen. Zudem sei eine zusätzliche Prüfung durch das Parlament gut. ${ }^{137}$ Bundeskanzler Gerhard Schröder hat sich, wie bereits zuvor der bayerische Ministerpräsident Edmund Stoiber, für ein Entsendegesetz ausgesprochen, das die Kompetenzen von Regierung und Parlament bei Auslandseinsätzen regeln und den jetzigen Parlamentsvorbehalt abschwächen soll. Die Position der GRÜNEN, die Rolle des Bundestages mit einer Zweidrittelmehrheit stärken zu wollen, halte er für falsch. Das Parlament solle auch weiterhin so weit es gehe informiert und beteiligt werden. So sei auch ein Rückholrecht denkbar. Derzeit lasse die Regierung dem Parlament jedoch mehr Kompetenzen als es verfassungsrechtlich geboten sei. ${ }^{138}$

Während Bündnis 90 / Die Grünen ein vollständiges Rückholrecht für den Bundestag gefordert haben, ${ }^{139}$ band die SPD diese Frage zunächst an einen zeitlich unbegrenzt genehmigten Einsatz, bei dem nach Ablauf eines Jahres über seine Fortsetzung zu entscheiden wäre. ${ }^{140} \mathrm{Im}$ gemeinsamen Entwurf der Regierungsparteien hat sich die Koalition auf die Position des kleineren Partners festgelegt. ${ }^{141}$ Die CDU/CSU macht das Begehren des Bundestages auf Beendigung eines laufenden Einsatzes davon abhängig, ob diesem Antrag nicht völkerrechtliche Verpflichtungen der Bundesrepublik entgegenstehen, und verlangt für die Zulässigkeit eines solchen Antrags die Zustimmung der Mehrheit der gesetzlichen Mitglieder des Bundestages. ${ }^{142}$ Die FDP

135 Gesetzentwurf der Abgeordneten und der Fraktion der FDP (Fn. 8), Abs. 3 der Erläuterungen zu $\S 6$.

136 Ursula Knapp, Wenn Volksvertreter schwer an ihren Rechten tragen, Frankfurter Rundschau, 21.08.2001; Gerold Büchner, Am Parlamentsvorbehalt zweifeln viele, Berliner Zeitung, 20.08.2001. Gerold Büchner, Auslandseinsätze: Regierung soll allein entscheiden, Berliner Zeitung, 20.08.2001. Vgl. auch Peter Dreist a. a. O. (Fn. 1), S. 134 f.

137 dpa-Agenturmeldung vom 21.08.2001: Entscheidung über Mazedonien-Einsatz der Bundeswehr rückt näher.

138 Werner Kohlhoff, Schröder hält an der Wehrpflicht fest - Kanzler will Entsendegesetz für Auslandseinsätze, Berliner Zeitung, 09.04.2002, S. 5.

139 Positionspapier der Bundestagsfraktion Bündnis 90 / Die Grünen (Fn. 8), Ziffer 2.2.

140 Entwurf der SPD-Bundestagsfraktion (Fn. 8), § 7.

141 Gemeinsamer »Entwurf von SPD und Bündnis 90/Grüne für ein Parlamentsbeteiligungsgesetz vom 27.11.2003 (Fn. 8), § 8 .

142 Undatierter Gesetzentwurf (Arbeitspapier) der Abgeordneten und der Fraktion der CDU/ CSU (Fn. 8), § 5 . 
schließlich will ein Rückholrecht dem Ausschuss für besondere Auslandseinsätze zubilligen, wenn es um einen Einsatz bei Gefahr im Verzug, um besondere Geheimhaltungsbedürftigkeit oder um die Teilnahme einzelner Soldaten an VN-, NATO- oder EU-Einsätzen geht. ${ }^{143}$ Falls der Bundestag bestimmte Entscheidungen an sich gezogen habe, solle dem Plenum und nicht dem Ausschuss das Rückholrecht zustehen. Die Ausübung des Rückholrechts durch Antrag auf Widerruf des Einsatzes müsse von einem Viertel der Mitglieder des Bundestages unterstützt werden. ${ }^{144}$

\section{c. Konsensmöglichkeiten}

Da bereits in einer ganzen Anzahl von Einzelfragen entweder Konsens zwischen den Parteien besteht oder ein solcher Konsens zumindest möglich erscheint, ${ }^{145}$ und da außerdem in weiteren Einzelfragen trotz abweichender Standpunkte in den bisherigen Vorschlägen des parlamentarischen Raumes die Lösungen durch Verfassungsrichterrecht bereits vorgegeben sind, sollte eine Verständigung auf Regelungen, die eine wirkliche Vereinfachung des bisherigen ungeregelten Verfahrens führen und die damit für einen wesentlichen Zuwachs an Rechtsklarheit sorgen, möglich sein. Dabei ist auch die verfassungsrichterliche Vorgabe für die Regelung des Beteiligungsverfahrens in einem Bundesgesetz zu beachten. ${ }^{146}$ Deshalb ist die immer wieder ins Gespräch gebrachte Option einer Regelung der einschlägigen Fragen ausschließlich in der Geschäftsordnung des Bundestages in diesem Fall versperrt. ${ }^{147}$

Das Gesetz sollte ferner dem aktuellen Stand der Erkenntnisse, insbesondere im Hinblick auf die Rechtsprechung des Bundesverfassungsgerichts, aber auch im Hinblick auf die offenen Fragen, die in den Jahren seit dem 12. Juli 1994 in der Praxis erkannt worden sind, entsprechen. Die Spielräume, die danach für die Grenzziehung zwischen dem »Einsatz bewaffneter Streitkräfte« im Rechtssinne und solche Verwendungen, die diese Schwelle noch nicht erreichen, bestehen, sollten ebenfalls zur Vereinfachung genutzt werden. Die Frage des »Einsatzes von geringer Bedeutung «, für die das Bundesverfassungsgericht eine abgestufte, also unterhalb der Schwelle des Art. 42 Abs. 2 GG einschließlich der Befassung der Fachausschüsse angesiedelte Beteiligungsintensität angeregt hat, wäre ebenso zu regeln wie die Zuständigkeiten eines »Einsatzausschusses«, der im Falle von Geheimhaltungs- und Eilbedürftigkeit ebenso wie bei Einsätzen von geringer Bedeutung an Stelle des Plenums Ansprechpartner der Bundesregierung sein könnte. Das von van Essen formulierte Postulat »im

143 Gesetzentwurf der Abgeordneten und der Fraktion der FDP (Fn. 8), § 6 Abs. 1 a bis c.

144 Gesetzentwurf der Abgeordneten und der Fraktion der FDP (Fn. 8), § 4 Abs. 2.

145 Vgl. Fn. 106 bis 115.

146 BVerfGE 90, $286[389,390]$ überträgt diese Aufgabe dem Gesetzgeber. »Es ist Sache des Gesetzgebers, die Form und das Ausmaß der parlamentarischen Mitwirkung näher auszugestalten..... Ungeachtet der Gestaltungsfreiheit im Einzelnen muss die gesetzliche Regelung das Prinzip förmlicher parlamentarischer Beteiligung hinreichend zur Geltung bringen. Andererseits hat sie auch den von der Verfassung für Außenpolitisches Handeln gewollten Eigenbereich exekutiver Handlungsbefugnis und Verantwortlichkeit $\mathrm{zu}$ beachten (....BVerfGE 68, 1 [86]).« (Hervorhebungen durch den Autor).

147 DVParl-Protokoll vom 04.06.2003, dort Prof. Josef Isensee, S. 41. 
Zweifel für die Parlamentsbeteiligung ${ }^{148}{ }^{148}$ sollte ebenso verankert werden wie es notwendig sein wird, ergänzend zum Parlamentsbeteiligungsgesetz die Geschäftsordnung des Deutschen Bundestages um einem Abschnitt zur verfahrensmäßigen Umsetzung des neuen Gesetzes, das sich dann nicht mehr an den Regelungen des Gesetzgebungsverfahrens orientieren wird, anzupassen. ${ }^{149}$

Dagegen sollten Fälle von Gefahr im Verzug weiterhin im Handlungsspektrum der Bundesregierung verbleiben; allenfalls könnten Informationspflichten und ein bestimmter Zeitpunkt festgelegt werden, zu dem spätestens die konstitutive Befassung des Bundestages erfolgen muss. Eine ergänzende Regelung für ein Rückrufrecht ist angesichts der verfassungsrichterlichen Vorgaben nur beschränkt möglich; deshalb sollte die Maximalforderung für ein unbeschränktes Rückrufrecht nicht weiter verfolgt werden. Im folgenden Abschnitt zu den offenen Fragen aus der Praxis werden Regelungen vorgeschlagen, die den vorstehenden Vorschlägen entsprechen.

\section{Notwendige Inhalte eines Gesetzentwurfes}

Die Einhaltung der Vorgaben des Völkerrechts und des Verfassungsrechts können in einem Parlamentsbeteiligungsgesetz nicht geregelt werden; ein Einsatz muss völkerrechtlich erlaubt sein, um verfassungsrechtlich überhaupt statthaft sein zu können. ${ }^{150} \mathrm{Ob}$ ein Einsatz verfassungsgemäß ist, richtet sich nach den Vorgaben des Grundgesetzes und des insoweit ergangenen Verfassungsrichterrechts. ${ }^{151}$ Die Detailregelungen müssen in einer Reihe von Fällen angesichts der Probleme aus der bisherigen Staatspraxis jedoch zwingend weiter gehen als der Inhalt der bisher vorgelegten Entwürfe. Der Wunsch, offene Fragen zu regeln, dabei aber ein erhebliches Maß an inhaltlicher Offenheit ${ }^{152}$ durch allgemeine Formulierungen und unbestimmte Rechtsbegriffe zu erreichen, findet seine Grenzen bei der Formulierung notwendiger neuer Regelungen z. B. zu einem Rückholrecht, bei Legaldefinitionen oder dem sog. »Einsatz von geringer Bedeutung.«

Die nachstehenden Ausführungen enthalten zum besseren Verständnis die Fundstellen des unter 9. vorgeschlagenen Gesetzentwurfs, wobei der Entwurf selbst in eckigen Klammern Alternativvorschläge enthält; der eigentliche Text wird favorisiert. Ein Parlamentsbeteiligungsgesetz sollte den Grundsatz betonen, dass »Einsätze bewaffneter Streitkräfte« im Rechtssinne (Einsatz) der grundsätzlich vorherigen konstitutiven Zustimmung des Deutschen Bundestages (Plenum) bedürfen ( $§ 1$ ). Das Gesetz sollte eine Regelung enthalten, was als Einsatz anzusehen ist ( 2 Abs. 1 und 2) und welche

148 DVParl-Protokoll vom 04.06.2003, dort Jörg van Essen, S. 16 u. 19.

149 DVParl-Protokoll vom 04.06.2003, dort Jörg van Essen, S. 31.

150 Zutreffend insoweit das Positionspapier der Bundestagsfraktion Bündnis 90 / Die Grünen (Fn. 8), 1. Ziel eines Parlamentsbeteiligungsgesetzes, »Was wir nicht regeln können«.

151 Vgl. Peter Dreist a. a. O. (Fn. 26), S. 157 ff.

152 DVParl-Protokoll vom 04.06.2003, dort Prof. Rupert Scholz, S. 7, 9 sowie 34 und 39; vgl. auch dort Dieter Wiefelspütz, S. 36, sowie Dieter Weingärtner, S. 45, der dafür eintritt, dass die Schwierigkeiten, die sich aus der Staatspraxis ergeben haben, so weit es geht ausgeräumt werden. 
Fälle nicht als Einsatz in diesem Sinne gelten ( $\$ 2$ Abs. 3 - erste grundlegende Verfahrensvereinfachung; als Alternative wird die konstitutive Zustimmung fingiert). In den Fällen des $\S 2$ Abs. 3 a bis c wird nicht der Grad der Gefahr der Einbeziehung deutscher Soldaten in bewaffnete Unternehmungen erreicht, in der sich ein militärtypisches und damit staatsrechtlich relevantes Kriegsrisiko oder - in Friedensmissionen - das Risiko bewaffneter Auseinandersetzungen von einigem Gewicht verwirklicht.

Das Gesetz enthält ferner nähere inhaltliche Vorgaben für den Antrag der Bundesregierung an den Deutschen Bundestag auf der Grundlage eines bereits als bewährt anzusehenden Verfahrens ( $(3)$, Regelungen über Berufung und Arbeitsdauer des Einsatzausschusses als neuer, für die konstitutive Zustimmung des Parlaments in bestimmten Fällen allein zuständiger Ausschuss ( $(4)$, seine Aufgaben ( $\$ 5$ - zweite Verfahrensvereinfachung) sowie das neue Verfahren im Plenum (\$6-dritte Verfahrensvereinfachung). Dem Grundsatz »Im Zweifel für die Parlamentsbeteiligung « wird durch folgende Regelungen Rechnung getragen: Eine Befassung des Plenums ist vorgesehen, wenn eine Fraktion oder ein Viertel der gesetzlichen Mitglieder des Bundestages äußern, eine Verwendung im Sinne des $\S 2$ Abs. 3 a bis c sei in Wirklichkeit ein Einsatz ( $\$ 2$ Abs. 4), oder wenn ein Viertel der Mitglieder des Einsatzausschusses begründete Zweifel an der Zulässigkeit der konstitutiven Zustimmung im »vereinfachten Verfahren« (= Zustimmung durch den Einsatzausschuss) äußern ( 5 Abs. 4). In diesen Fällen wird genauso verfahren wie bei der Befassung des Plenums bei einem Einsatz im Rechtssinne nach $\S 6$ Abs. 1 bis 4 ( 6 Abs. 5).

Das (übliche) Verfahren bei der konstitutiven Zustimmung zu einem Antrag der Bundesregierung zu einem Einsatz im Rechtssinne sieht jedoch nunmehr zuerst die Befassung der Ausschüsse, danach nur noch eine anschließende Lesung sowie die namentliche Abstimmung vor ( $\$ 6$ Abs. 1 - vierte Verfahrensvereinfachung). Die Verteilung von Federführung und Beteiligung weiterer Ausschüsse ( $\$ 6$ Abs. 2 und 3) einschließlich des Haushaltsausschusses ( $\$ 6$ Abs. 4) entspricht dem bewährten Verfahren.

Für Entscheidungen in einem Fall von Gefahr im Verzug wird materiell auch der Fall einbezogen, dass Sicherheit und Leben deutscher Staatsbürger in einem anderen Staat wie im Fall LIBELLE gefährdet sind und nur durch einen Streitkräfteeinsatz gerettet werden können, was in der Staatspraxis als Fall von Gefahr im Verzuge anerkannt wurde ( $\$ 7$ Abs. 1 c). Neu ist die Pflicht der Bundesregierung, sobald wie möglich den Einsatzausschuss $\mathrm{zu}$ unterrichten ( $\$ 7$ Abs. 2) und die konstitutive Zustimmung (des Plenums gem. § 6) spätestens zwei Wochen nach der Entscheidung nachzuholen.

$\S 8$ enthält Unterrichtungspflichten der Bundesregierung gegenüber dem Bundestag, die im Prinzip bewährter Übung entsprechen. Neu ist das Antragsrecht des Einsatzausschusses zur Akteneinsicht in die Akten, die von ihm genehmigte Einsätze betreffen und das weitere Antragsrecht, einzelne Mitarbeiter der Bundesministerien anzuhören $(\S 8$ Abs. 3). § 9 regelt die Behandlung von Geheimvorgängen durch den Einsatzausschuss.

Zur Frage eines Rückholrechts: An seine einmal erteilte Zustimmung ist der Bundestag grundsätzlich gebunden ( $§ 10$ Abs. 1). Verweigert der Bundestag seine nachträgliche Zustimmung zu einem Einsatz bei »Gefahr im Verzug «, sind die eingesetzten Kräfte von der Bundesregierung zurückzurufen (§ 10 Abs. 2 - unechtes 
Rückholrecht). Wird die beantragte Zustimmung zur Verlängerung eines bereits laufenden, befristeten Einsatzes verweigert, hat die Bundesregierung die Streitkräfte nach Ablauf der Frist aus dem Einsatzgebiet zurückzubeordern und den Einsatz zu beenden (§ 10 Abs. 3). § 10 Abs. 4 enthält den Fall eines echten Rückholrechts im Rahmen der verfassungsrichterlichen Spielräume: Haben sich die Voraussetzungen für den konkreten, bereits seit längerem laufenden Einsatz grundlegend geändert und beantragt eine Fraktion oder mindestens ein Viertel der gesetzlichen Mitglieder des Bundestages nach Aussprache im Plenum die unverzügliche Beendigung des Einsatzes, ist der Einsatz zu beenden und sind die Streitkräfte zurückzubeordern, falls der Deutsche Bundestag die Beendigung dieses Einsatzes mit der Mehrheit seiner gesetzlichen Mitglieder beschließt. Diese qualifizierte Mehrheit erscheint angesichts der weitreichenden Folgen einer solchen Entscheidung erforderlich. Das Gesetz tritt am Tag nach seiner Verkündung in Kraft ( $\$ 11)$. Es lautet:

\section{Gesetzentwurf}

Gesetz zur Regelung des Beteiligungsverfahrens zwischen der Bundesregierung und dem Deutschen Bundestag bei Entscheidungen über einem Einsatz bewaffneter deutscher Streitkräfte im Ausland (Parlamentsbeteiligungsgesetz - ParlBG) ${ }^{153}$

\section{$\S 1$ Grundsatz}

Der Einsatz bewaffneter deutscher Streitkräfte außerhalb des Geltungsbereichs des Grundgesetzes (Einsatz) bedarf der - grundsätzlich vorherigen - konstitutiven Zustimmung (Zustimmung) des Deutschen Bundestages, die von der Bundesregierung beantragt wird. ${ }^{154}$

\section{$\S 2$ Einsatz}

(1) Ein Einsatz liegt vor, wenn Soldaten der Bundesrepublik Deutschland an einem internationalen bewaffneten Konflikt beteiligt sind oder eine Verstrickung - auch einzelner Soldaten in Austauschprogrammen oder unbewaffneter AWACS-Besatzungen - in bewaffnete Auseinandersetzungen während eines solchen Konflikts zu besorgen ist. ${ }^{155}$

153 Dieser Titel ist präziser als »Entsendegesetz«, da das Verfahren der Beteiligung des Deutschen Bundestages bei der unmittelbar kraft Verfassung geltenden konstitutiven Zustimmung zu Einsätzen bewaffneter Streitkräfte geregelt werden soll (vgl. auch BVerfGE 90, $286[390])$.

154 BVerfGE 90, 286 [381 ff., 387 ff.].

155 Vgl. BVerfG a. a. O. (Fn. 48), Rn. 33 - 35 - ein Einsatz bewaffneter Streitkräfte liegt bei der Beteiligung an einem internationalen bewaffneten Konflikt (formales Kriterium) bereits deshalb vor, weil jeder Soldat einer beteiligten Partei nach den Regelungen des humanitären Völkerrechts Kombattant und damit rechtmäßiges Ziel gegnerischer Kampfhandlungen ist. Diese Beteiligung wird auch bei der Verstrickung in bewaffnete Unternehmungen - auch einzelner Soldaten in Austauschprogrammen oder unbewaffneten AWACS-Besatzungen erreicht. 
(2) Als Einsatz bewaffneter Streitkräfte gilt ferner die Beteiligung an Friedensmissionen im Rahmen von Systemen kollektiver Selbstverteidigung, insbesondere zum Schutz eines Bündnispartners, oder gegenseitiger kollektiver Sicherheit im Sinne des Artikels 24 Absatz 2 des Grundgesetzes. ${ }^{156}$

(3) Folgende Verwendungen gelten nicht als Einsatz [Die Zustimmung des Deutschen Bundestages gilt als erteilt in folgenden Fällen]: ${ }^{157}$

a. Die Beteiligung deutscher Streitkräfte an Hilfsdiensten und Hilfeleistungen im Ausland, auch wenn diese Handfeuerwaffen zum Eigen- und Materialschutz mit sich führen; ${ }^{158}$

b. die Beteiligung einzelner Soldaten in Austauschprogrammen verbündeter Streitkräfte ${ }^{159}$

c. die Entsendung von jeweils bis zu $20[25,30]^{160}$ Soldaten mit Handfeuerwaffen zum Eigen- und Materialschutz für die Dauer von höchstens einem Monat zu Beginn oder während eines Einsatzes als

156 BVerfGE 90, 286 [387/388].

157 Bei beiden Alternativen handelt es sich um eine Fiktion; stellt man sich auf den modernen Standpunkt, dies seien keine Einsätze mit der »Schwellenwirkung « des Kriegseinsatzes, weil ein kriegstypisches Risiko noch nicht verwirklicht werde, würden sie künftig nicht länger als Einsätze im Rechtssinne (1. Alternative) gewertet, obwohl das reine Faktum der Bewaffnung auch eine Einstufung als Einsatz im Rechtssinne zuließe. Sieht man solche Einsätze gleichwohl als Einsätze bewaffneter Streitkräfte im Rechtssinne an, hilft die zweite Alternative, die lediglich die Zustimmung des Plenums fingiert und damit die Bundesregierung im Rahmen ihrer exekutiven Eigenverantwortung ein Stück weit handlungsfähiger als bisher macht. Die Regelungen der Buchstaben a bis c i. bis iv. enthalten »Einsätze von geringer Bedeutung « im Sinne der Entscheidung BVerfGE 90, 286 [389], c v. enthält eine Regelung für eine während eines Einsatzes außerhalb des Einsatzgebiets notwendige kurzfristige Hilfsaktion. Durch diesen Abs. 3 könnte der gemeinsame »Entwurf von SPD und Bündnis 90/Grüne für ein Parlamentsbeteiligungsgesetz vom 27.11.2003 «(Fn. 8), § 4, ergänzt werden.

158 Nach BVerfGE 90, 286 [388] gilt nicht als Einsatz die Beteiligung an Hilfsdiensten und Hilfeleistungen im Ausland, sofern die Soldaten dabei nicht in bewaffnete Unternehmungen einbezogen sind. Vergleicht man dies mit der Formulierung, dass der wehrverfassungsrechtliche Parlamentsvorbehalt in der Begründung auf das klassische Bild eines Kriegseintrittszugeschnitten ist, entspricht die vorgeschlagene Formulierung der modernen und auch schon im parlamentarischen Raum geäußerten Auffassung, das Mitführen von Handfeuerwaffen zum Eigen- und Materialschutz löse den Parlamentsvorbehalt wegen seiner geringen Schwelle noch nicht aus. Siehe auch Entwurf der SPD-Bundestagsfraktion (Fn. 8), § 2 Abs. 2, sowie gemeinsamer »Entwurf von SPD und Bündnis 90/Grüne für ein Parlamentsbeteiligungsgesetz vom 27.11.2003 «(Fn. 8), § 2 Abs. 2. Auch mit dem undatierter Gesetzentwurf (Arbeitspapier) der Abgeordneten und der Fraktion der CDU/CSU (Fn. 8), § 2 Satz 2, ließe sich der Vorschlag vereinbaren, da die Anwendung von Waffengewalt im Sinne kriegerischer Auseinandersetzungen eine wesentlich höhere Eskalationsschwelle darstellt als die reine Selbstverteidigung.

159 Der Abzug eines einzelnen Funktionsoffiziers aus einer schwimmenden oder fliegenden Einheit sorgt oft für erhebliche Verstimmung bei den Alliierten; diese Art der Beteiligung eines einzelnen Soldaten an einem Einsatz sollte im Interesse der Bündnisfähigkeit künftig generell erlaubt werden. Vgl. auch BVerfGE 90, 286 [389].

160 Eine Festlegung einer niedrigeren Anzahl als 20 Soldaten wäre nicht effektiv; weitere Begrenzungen werden durch die beschränkt zugelassenen Zwecke (Eigen- und Materialschutz), die Art der zugelassenen Bewaffnung (Handfeuerwaffen) sowie die zeitliche Beschränkung auf höchstens einen Monat erreicht. 
i. Fact Finding Team,

ii. Vorkommando,

iii. Erkundungskommando,

iv. Führungs-, Sicherungs-, Stabs-, Fernmelde- oder sonstiges Unterstützungspersonal für internationale Hauptquartiere in einem Einsatzgebiet oder

v. bewaffnete Selbstschutzkomponente für einen kurzfristigen Hilfseinsatz ${ }^{161}$ sowie

d. [die Beteiligung an und die Organisation von Planungs-, Vorbereitungs-, Übungs-, Ausbildungs- und Manöveraktivitäten im Inland - auch zur Vorbereitung auf einen konkreten Einsatz. $]^{162}$

(4) Im Zweifel gilt eine Verwendung deutscher Soldaten im Ausland als Einsatz. Äußert eine Fraktion oder mindestens ein Viertel der gesetzlichen Mitglieder des Bundestages, eine Verwendung im Sinne des Absatzes 3 a bis c sei in Wirklichkeit ein Einsatz, leitet die Bundesregierung dem Deutschen Bundestag einen Antrag gemäß $\S 3 \mathrm{zu}$. Das Verfahren im Plenum regelt $\S 6 .{ }^{163}$

\section{$\S 3$ Antrag der Bundesregierung}

(1) Die Bundesregierung übersendet dem Deutschen Bundestag den Antrag auf Zustimmung zu Einsätzen rechtzeitig vor Beginn des Einsatzes.

(2) Der Antrag der Bundesregierung enthält insbesondere Angaben über

a. die rechtlichen Grundlagen des Einsatzes,

b. den Einsatzauftrag,

c. die Ermächtigung für den Bundesminister der Verteidigung, die einzusetzenden Kräfte im Einvernehmen mit dem Bundesminister des Auswärtigen einem System gegenseitiger kollektiver Sicherheit oder kollektiver Selbstverteidigung, falls der Einsatz in dessen Rahmen stattfinden soll, anzuzeigen sowie nach Zustimmung des Deutschen Bundestages einzusetzen,

d. Beginn und geplante Dauer des Einsatzes,

e. die für den Einsatz geplanten militärischen Fähigkeiten,

f. Status und Rechte der eingesetzten Soldaten,

g. das Einsatzgebiet,

161 Dies sind eine Reihe von Kleinsteinsätzen, die aus der Sicht der bisherigen Staatspraxis als sog. »Einsätze von erkennbar geringer Bedeutung « eingestuft werden könnten, oft ad hoc auftreten und in der Staatspraxis die meisten Schwierigkeiten verursachen. Vgl. auch BVerfGE 90, 286 [389].

162 Dies sind offensichtlich keine Einsätze; vgl. auch Dieter Wiefelspütz (Beteiligung), S. 139, weil die Soldaten erkennbar zu Planungs- und Übungsaktivitäten herangezogen werden und in diesem Rahmen auch gar nicht im technischen Sinne »eingesetzt « werden sollen; zudem sind sie nicht in Kampfhandlungen einbezogen. Damit hat die Regelung eher klarstellenden und abgrenzenden Charakter, allerdings auf einem bisher völlig ungeregelten Feld. Buchstabe d könnte ersatzlos entfallen, wenn die Klammer-Alternative der fingierten Zustimmung des Plenums verwirklicht würde.

163 Diese Regelung entspricht der Forderung nach einer Bestimmung, die den Grundsatz »im Zweifel für die Parlamentsbeteiligung « zum Ausdruck bringt; vgl. auch Fn. 149. 
h. Art und Höchstzahl der einzusetzenden Soldaten sowie

i. die voraussichtlichen Kosten des Einsatzes. ${ }^{164}$

(3) Änderungen des Antrages durch den Deutschen Bundestag sind unzulässig. ${ }^{165}$

(4) Für den Antrag im Falle des $§ 2$ Absatz 4 ist Absatz 1 bis 3 entsprechend anzuwenden. ${ }^{166}$

\section{$\S 4$ Einsatzausschuss}

(1) Der Deutsche Bundestag wählt zu Beginn einer Legislaturperiode die Mitglieder eines Ausschusses für die verbindliche Abgabe der Zustimmung zu Einsätzen (Einsatzausschuss) einschließlich der Ersatzmitglieder. Den Vorsitz übernimmt [kraft seines/ihres Amtes] der Präsident/die Präsidentin des Deutschen Bundestages. Der Einsatzausschuss besteht insgesamt aus höchstens neun [elf, dreizehn] ordentlichen und ebenso vielen Ersatzmitgliedern. Jede Fraktion ist durch wenigstens ein Mitglied im Einsatzsausschuss vertreten; Mitglieder des Deutschen Bundestages ohne Fraktionsstatus sind nicht wählbar.

(2) Der Einsatzausschuss wird erstmals am Tage des Inkrafttretens dieses Gesetzes gewählt; er übt seine Tätigkeit auch über das Ende einer Wahlperiode hinaus solange aus, bis der Bundestag gemäß Absatz 1 erneut entschieden hat. ${ }^{167}$

\section{$\S 5$ Aufgaben des Einsatzausschusses}

(1) Der Einsatzausschuss wird ermächtigt, einem Antrag der Bundesregierung zu einem Einsatz nach Aussprache in einer Ausschusssitzung die Zustimmung zu erteilen (vereinfachtes Verfahren), falls die Bundesregierung

a. ihren Antrag als Verschlusssache des Geheimhaltungsgrades GEHEIM und höher eingestuft hat,

b. ihren Antrag als besonders eilbedürftig bezeichnet hat, ohne dass Geheimhaltungsgründe bestehen oder eine Gefährdung der Wehr- oder Bündnisfähigkeit der Bundesrepublik Deutschland zu besorgen ist, ${ }^{168}$

164 Die Regelungen entsprechen der allgemein als bewährt angesehenen Staatspraxis für den Initiativbeschluss bei einem neuen Einsatz; vgl. auch Fn. 39.

165 BVerfGE 90, 286 [389): Danach kann die Zustimmung versagt oder erteilt werden. Im Falle von Gefahr im Verzug kann auch durch Nichtzustimmung der Einsatz unterbunden werden. Eine Initiativbefugnis steht dem Parlament nicht zu.

166 Diese Regelung ist erforderlich, weil im Fall des $§ 2$ Abs. 4 auf Wunsch einer Fraktion oder mindestens eines Viertels der gesetzlichen Mitglieder des Bundestages ein Vorgang zu einem Zustimmungsantrag der Bundesregierung führt, der dort ursprünglich nicht vorgesehen war.

167 Die Regelung entspricht weitgehend den Vorstellungen, die von der FDP vorgelegt wurden, die bisher als einzige Partei nähere Vorstellungen zur Konstituierung eines solchen Ausschusses geäußert hat. Vgl. auch Gesetzentwurf der Abgeordneten und der Fraktion der FDP (Fn. 8), §5.

168 Die Abschichtung dieser Entscheidungen auf einen Einsatzausschuss ermöglicht die Erteilung der konstitutiven Zustimmung vor Einsatzbeginn und entspricht damit den Vorgaben des Bundesverfassungsgerichts, in einem Gesetz auch den Fall von Einsätzen, »die keinen Aufschub dulden, « näher zu bestimmen, ohne dass die Gefahr-im-Verzug-Regelung in Anspruch genommen werden muss (BVerfGE 90, 286 [389]). Damit hat ein Einsatzausschuss wirkliche konstitutive Aufgaben, die gleichzeitig eine starke Verfahrensvereinfa- 
c. die erstmalige parlamentarische Zustimmung $\mathrm{zu}$

i. einem isolierten Einsatz von bis zu 100 Soldaten für einen Zeitraum von bis zu einem Jahr, ${ }^{169}$

ii. einem Einsatz einzelner Soldaten im Rahmen einer Operation der Vereinten Nationen, der NATO, der EU oder eines anderen Systems gegenseitiger kollektiver Sicherheit oder Verteidigung, dessen Mitglied die Bundesrepublik Deutschland ist oder wird ${ }^{170}$

iii. einem Einsatz von bis zu 50 Soldaten in den Fällen des § 2 Absatz 3 a bis c, ${ }^{171}$

iv. einem Einsatz in den Fällen des $\S 2$ Absatz 3 a bis c, der länger als einen Monat bis zu zwei Monaten dauert, ${ }^{172}$ oder

d. einer Verlängerung eines bereits gebilligten Einsatzes unter Beibehaltung aller bisherigen Regelungen ${ }^{173}$ beantragt und dies entsprechend begründet.

(2) Der Einsatzausschuss trifft seine Entscheidungen mit der Mehrheit der abgegebenen Stimmen. ${ }^{174}$

chung darstellen. Dies wäre auch der rechtliche Weg, für die ad hoc notwendige Beteiligung an einem eilbedürftigen Einsatz - sei es im Rahmen der NATO Response Force, der VNstand by arrangements, einer EU-Eingreiftruppe oder nationalen Evakuierungseinsätzen sogar vor Einsatzbeginn die konstitutive Zustimmung eines kleinen und der Geheimhaltung besonders verpflichteten Gremiums und damit parlamentarische Legitimation zu erhalten.

169 Als Beispiele für solche Einsätze sind die deutsche Beteiligung an INTERFET in Ost-Timor (BT-Drs. 14/1719 vom 06.10.1999, Zustimmung des Deutschen Bundestages vom 07.10.1999, Ziffer 5 Satz 1 - gebilligt wurde der Einsatz von bis zu 100 deutschen Soldaten) sowie die deutsche Beteiligung an der EU-Operation Concordia in Mazedonien (BT-Drs. 15/696 vom 19.03.2003, Zustimmung des Deutschen Bundestages am 20.03.2003, Ziffer 8 Abs. 1 - gebilligt wurde der Einsatz von bis zu 70 deutschen Soldaten) anzusehen; sie haben also durchaus Praxisrelevanz.

170 Dies erweitert einerseits die Anzahl der Fälle, in denen es sich in der Sache um einen Einsatz von geringer Bedeutung handelt; der Fall des Absatz $1 \mathrm{c}$ ii. wurde als Einsatz von geringer Bedeutung sowohl von der FDP (Gesetzentwurf der Abgeordneten und der Fraktion der FDP [Fn. 8], § 6 Abs. 1 c.) als auch von der SPD (Entwurf der SPD-Bundestagsfraktion [Fn. 8], § 4 Abs. 2 Nr. 3) eingebracht. Inzwischen wurde diese Fallkonstellation auch im gemeinsamen »Entwurf von SPD und Bündnis 90/Grüne für ein Parlamentsbeteiligungsgesetz vom 27.11.2003 (Fn. 8), § 4 Abs. 3, dritter Spiegelstrich, übernommen.

171 In diesem Fall wird die konstitutive Zustimmung, wenn auch in einem vereinfachten Verfahren durch den Entsendeausschuss, ergänzend vorgesehen in Fällen, in denen für einen Einsatz von geringer Bedeutung im Sinne des $§ 2$ Abs. 3 a bis c bis zu 50 Soldaten benötigt werden.

172 In diesem Fall wird die konstitutive Zustimmung ergänzend vorgesehen in Fällen, in denen ein Einsatz von geringer Bedeutung im Sinne des $§ 2$ Abs. 3 a bis c bis zu zwei Monaten dauert.

173 Nach dem Vorschlag von Bündnis 90 / Die Grünen sollte dieser Fall allerdings dem Auswärtigen Ausschuss, nicht einem Einsatzausschuss übertragen werden (Positionspapier der Bundestagsfraktion Bündnis 90 / Die Grünen (Fn. 8], Ziffer 2.4). Vgl. ferner Gesetzentwurf der Abgeordneten und der Fraktion der FDP (Fn. 8), Erläuterungen zu § 6, dort Abs. 3 am Ende. Inzwischen schlägt der gemeinsame »Entwurf von SPD und Bündnis 90/Grüne für ein Parlamentsbeteiligungsgesetz vom 27.11.2003« (Fn. 8), § 7, immerhin die Anwendung des dort in $\S 4$ geregelten »Vereinfachten Zustimmungsverfahrens « vor.

174 Dies entspricht der Regelung für das Plenum. 
(3) Äußert mindestens ein Viertel der Mitglieder des Ausschusses begründete Zweifel an der Zulässigkeit der Zustimmung im vereinfachten Verfahren, wird der Antrag der Bundesregierung dem Plenum zur Zustimmung im üblichen Verfahren zugeleitet. ${ }^{175}$

§ 6 Entscheidung durch das Plenum

(1) Die Entscheidung des Deutschen Bundestages über den Antrag der Bundesregierung zu einem Einsatz wird durch das Plenum nach vorheriger Befassung der Fachausschüsse und anschließender Lesung mit der Möglichkeit einer Aussprache durch namentliche Abstimmung (übliches Verfahren) getroffen. Die Zustimmung wird mit der Mehrheit der abgegebenen Stimmen erteilt; wird diese Mehrheit verfehlt, ist der Antrag abgelehnt. ${ }^{176}$

(2) Federführend ist der Auswärtige Ausschuss; beteiligt sind immer der Verteidigungs- und der Rechtsausschuss sowie der Ausschuss für Menschenrechte und humanitäre Hilfe und der Ausschuss für wirtschaftliche Zusammenarbeit und Entwicklung. Die Beteiligung weiterer Ausschüsse wird durch den federführenden Ausschuss fallweise festgelegt.

(3) Jeder Ausschuss votiert nach Aussprache gesondert; er kann das Votum mit besonderen Empfehlungen verbinden. Das Ergebnis leitet er dem federführenden Ausschuss zu.

(4) Der Haushaltsausschuss prüft nach der Geschäftsordnung des Bundestages, ob der Antrag der Bundesregierung mit der Haushaltslage des Bundes vereinbar ist und votiert gesondert. ${ }^{177}$

(5) Die Absätze 1 bis 4 werden in den Fällen des $\S 2$ Absatz 4 und $\S 5$ Absatz 4 entsprechend angewandt.

\section{$\S 7$ Gefahr im Verzug}

(1) Liegt Gefahr im Verzug für

a. die Wehrfähigkeit oder

b. die Bündnisfähigkeit der Bundesrepublik Deutschland ${ }^{178}$ oder

175 Diese Regelung eröffnet die Möglichkeit, bei begründeten Zweifeln am vereinfachten Verfahren das Plenum abstimmen zu lassen; diese Variante der konstitutiven Zustimmung ist immer statthaft. Sie entspricht im übrigen der Forderung »im Zweifel für den Parlamentsvorbehalt«, soweit darunter die Beteiligung des gesamten Plenums verstanden wird.

176 Durch die Einrichtung eines eigenen Verfahrens werden zweite und dritte Lesung eingespart. Die Befassung der Ausschüsse (vor der Abstimmung und der Erörterung im Plenum) im Sinne von BVerfGE 90, 286 (388) muss daher ohne vorherige Diskussion im Plenum erfolgen. Erst werden nach diesem neuen System die Ausschüsse befasst, danach erfolgt die Aussprache im Plenum mit unmittelbar anschließender namentlicher Abstimmung. Die Mehrheit ergibt sich aus dem Hinweis des Gerichts auf Art. 42 Abs. 2 GG. Wird die Mehrheit wie bei BT-Drs. 14/1111 vom 07.06.1999 verfehlt, ist der Antrag abgelehnt; eine Regelung dieser Frage fehlt bisher, muss aber bei der umfassenden Neuregelung des Beteiligungsprocederes berücksichtigt werden.

177 Die Absätze 2 - 4 entsprechen der bisherigen Staatspraxis und gelten nur für den Fall der Entscheidung durch das Plenum.

178 BVerfGE 90, 286 [388]. 
c. für die Sicherheit und das Leben deutscher Staatsbürger auf dem Territorium eines anderen Staates vor, und ist dieser Staat nicht bereit oder in der Lage, diese Menschen ausreichend zu schützen, ${ }^{179}$ ist die Bundesregierung berechtigt, vorläufig den Einsatz zu beschließen und an entsprechenden Beschlüssen in den Bündnissen oder internationalen Organisationen ohne Einhaltung der Vorgaben der $\S \S 1$ bis 6 mitzuwirken und diese vorläufig zu vollziehen.

(2) Der Einsatzausschuss ist sobald wie möglich in geeigneter Form zu unterrichten.

(3) Die Zustimmung des Deutschen Bundestages ist innerhalb eines angemessenen Zeitrahmens, spätestens nach zwei Wochen nach ihrer Entscheidung, nachzuholen.

(4) Wird die Zustimmung nicht erteilt, muss die Bundesregierung die Beendigung des Einsatzes unverzüglich veranlassen. ${ }^{180}$

\section{$\S 8$ Unterrichtung}

(1) Die Bundesregierung unterrichtet den Einsatzausschuss fortlaufend über die durch den Ausschuss genehmigten Einsätze.

(2) Nach Beendigung eines solchen Einsatzes legt die Bundesregierung dem Einsatzausschuss einen abschließenden Bericht vor. Dieser entscheidet über die Weiterleitung des Berichts an Fachausschüsse.

(3) Die Bundesregierung gewährt dem Einsatzausschuss auf seinen Antrag Einsicht in die Akten, die in unmittelbarem Zusammenhang mit vom Einsatzausschuss genehmigten Einsätzen stehen. Sie ermöglicht auf weiteren Antrag auch die Anhörung einzelner Mitarbeiter der beteiligten Ministerien. ${ }^{181}$

(4) Die Bundesregierung unterrichtet den Deutschen Bundestag fortlaufend, mindestens jedoch einmal im Monat, über die aktuelle Lage in den Einsatzgebieten, für die der Deutsche Bundestag einem Einsatz zugestimmt hat. Dies gilt auch in den Fällen des $\S 2$ Absatz 4 und $\S 5$ Absatz 4. Bei vom Deutschen Bundestag genehmigten Einsätzen sind nach Beendigung des Einsatzes Abschlussberichte an das Plenum zu erstatten.

\section{§9 Geheimhaltung}

(1) In den Fällen des $\S 5$ Absatz 1 a und b wird nach der Geheimschutzordnung des Bundestages verfahren.

(2) Der Einsatzausschuss erstattet dem Deutschen Bundestag in den Fällen des Absatzes 1 erst Bericht, nachdem die Einstufung der Unterlagen für diesen Einsatz als GEHEIM von der Bundesregierung aufgehoben worden ist. ${ }^{182}$

179 Fall der Operation LIBELLE, durch die Staatspraxis anerkannt (vgl. Fn. 27).

180 Die Regelung des Abs. 3 bestimmt einen festen Rahmen für die Forderung nach »umgehender« Unterrichtung durch das Bundesverfassungsgericht; Abs. 4 präzisiert mangels Initiativrecht des Bundestages, wer tätig werden muss.

181 Entspricht dem Gesetzentwurf der Abgeordneten und der Fraktion der FDP (Fn. 8), § 8.

182 Entspricht weitgehend dem Gesetzentwurf der Abgeordneten und der Fraktion der FDP (Fn. $8), \S 9$. 
$\S 10$ Rückholrecht

(1) Hat der Deutsche Bundestag einem unbefristeten Antrag der Bundesregierung zugestimmt, ist er an diese Zustimmung grundsätzlich gebunden. ${ }^{183}$

(2) In Fällen des $§ 7$ Absatz 4 sind die Streitkräfte von der Bundesregierung unverzüglich zurückzurufen (unechtes Rückholrecht). ${ }^{184}$

(3) Ist der Antrag der Bundesregierung auf Zustimmung zu einem konkreten Einsatz befristet, ist die erneute Zustimmung des Deutschen Bundestages zur Fortsetzung des Einsatzes rechtzeitig vor Ablauf der Frist einzuholen. Die Befristung kann sich aus dem Antrag oder einer Protokollerklärung ergeben. Wird die Zustimmung versagt, hat die Bundesregierung die Streitkräfte nach Ablauf der Frist aus dem Einsatzgebiet abzuziehen und den Einsatz zu beenden. ${ }^{185}$

(4) Absatz 3 ist entsprechend anzuwenden, falls

a. sich die Voraussetzungen für einen konkreten Einsatz grundlegend ändern und

b. deshalb eine Fraktion oder mindestens ein Viertel der gesetzlichen Mitglieder des Bundestages nach Aussprache im Plenum die unverzügliche Beendigung des Einsatzes beantragen und

c. falls der Deutsche Bundestag die Beendigung dieses Einsatzes mit der Mehrheit seiner gesetzlichen Mitglieder beschließt (echtes Rückholrecht). ${ }^{186}$

\section{$\S 11$ Inkrafttreten}

Dieses Gesetz tritt am Tage nach seiner Verkündung in Kraft.

\section{Ausblick}

Nach mehr als 10 Jahren Einsatzerfahrung (beginnend mit UNSCOM im Irak 1991 und UNAMIC und UNTAC in Kambodscha 1991/92) sowie der Erfahrung mit mehr als 30 Entscheidungen des Bundestages zu einem Einsatz bewaffneter Streitkräfte ist es an der Zeit, die Empfehlungen des Urteils des Bundesverfassungsgerichts vom 12. Juli 1994 umzusetzen. Dabei hat das Gericht Spielräume gelassen, die Bundesregierung und Bundestag ausfüllen dürfen. Der hier vorgeschlagene Entwurf ist mit 11

183 BVerfGE 90, 286 [388].

184 Bisher nicht geregelt; entspricht aber den Vorgaben in BVerfGE 90, 286 [388].

185 Die Regelung zeigt die Konsequenz für den Fall auf, dass ein ursprünglich genehmigter befristeter Einsatz für seine beantragte Verlängerung die konstitutive Zustimmung nicht erreicht.

186 Einziger Fall eines echten Rückholrechts, dessen Voraussetzungen erst gegeben sind, wenn alle Voraussetzungen des Absatzes 4 kumulativ erfüllt sind. Dies ist auch der Hauptanwendungsfall eines Rückholrechts, wie er im parlamentarischen Raum gefordert wird. An ein umfassendes Rückholrecht reicht er nahe heran, bindet die Entscheidung, die die Bundesregierung zu einem Abzug der Truppen aus dem Einsatzgebiet zwänge, aber an eine Reihe materieller Voraussetzungen. Solange keine grundlegende Änderung der Einsatzvoraussetzungen gegeben ist, ist materiell auch kein Rückholrecht erforderlich. 
Paragrafen vergleichsweise kurz und übersichtlich und dient den auch im Parlament artikulierten Zielen: Klarheit, Vereinfachung des Verfahren und Lösung von Fragen, die bisher im Zweifel den konkreten Einsatz einzelner Soldaten oder kleiner Gruppen von Soldaten gar nicht zugelassen haben. Dabei wird der von der Wehrverfassung vorgegebene konstitutive Parlamentsvorbehalt eingehalten, in bestimmten Fällen aber modifiziert. Deshalb gibt es drei unterschiedliche Verfahren: Einsätze, die nicht als solche gelten oder für die die Zustimmung des Bundestages fingiert wird, werden vom Kabinett beschlossen. Für eil- und geheimhaltungsbedürftige Einsätze und solche, die dem Einsatzausschuss aus sonstigen Gründen zugewiesen sind einschließlich solcher »von geringer Bedeutung «, entscheidet dieser nach einer Sitzung. Auch das Verfahren im Plenum bei den übrigen Entscheidungen wird gestrafft und vereinfacht.

Gleichzeitig wird der Forderung »Im Zweifel für den Parlamentsvorbehalt « entsprochen, weil auf Antrag das Plenum auch dann entscheidet, wenn Zweifel an den Kautelen der einfacheren Verfahren $\mathrm{zu}$ einem entsprechenden Antrag aus dem Einsatzausschuss oder dem Parlament führen. Die Regelungen für Gefahr im Verzug werden leicht modifiziert, ein Fall eines echten Rückholrechts neu eingeführt ( $\$ 10$ Abs. 4) und ein weiterer Fall eines Rückholrechts ausdrücklich geregelt, der bisher noch nie vorkam, aber denkbar ist (§10 Abs. 3). Man darf gespannt sein, wie sich die Diskussion um ein Parlamentsbeteiligungsgesetz weiter entwickeln wird. 